\title{
Active Roles of Electrically Coupled Bipolar Cell Network in the Adult Retina
}

\author{
Itaru Arai, Masashi Tanaka, and Masao Tachibana \\ Department of Psychology, Graduate School of Humanities and Sociology, The University of Tokyo, Bunkyo-ku, Tokyo 113-0033, Japan
}

Gap junctions are frequently observed in the adult vertebrate retina. It has been shown that gap junctions function as passive electrotonic pathways and play various roles, such as noise reduction, synchronization of electrical activities, regulation of the receptive field size, and transmission of rod signals to cone pathways. The presence of gap junctions between bipolar cells has been reported in various species but their functions are not known. In the present study, we applied dual whole-cell clamp techniques to the adult goldfish retina to elucidate the functions of gap junctions between ON-type bipolar cells with a giant axon terminal (Mb1-BCs). Electrophysiological and immunohistochemical experiments revealed that Mb1-BCs were coupled with each other through gap junctions that were located at the distal dendrites. The coupling conductance between Mb1-BCs under light-adapted conditions was larger than that under dark-adapted conditions. The gap junctions showed neither rectification nor voltage dependence, and behaved as a low-pass filter. $\mathrm{Mb1-BCs}$ could generate $\mathrm{Ca}^{2+}$ spikes in response to depolarization, especially under dark-adapted conditions. The $\mathrm{Ca}^{2+}$ spike evoked electrotonic depolarization through gap junctions in neighboring $\mathrm{Mb1-BCs,} \mathrm{and}$ the depolarization in turn could trigger $\mathrm{Ca}^{2+}$ spikes with a time lag. A brief depolarizing pulse applied to an $\mathrm{Mb} 1-\mathrm{BC}$ evoked a long-lasting EPSC in the postsynaptic ganglion cell. The EPSC was shortened in duration when gap junctions were pharmacologically or mechanically impaired. These results suggest that the spread of $\mathrm{Ca}^{2+}$ spikes through gap junctions between bipolar cells may play a key role in lateral interactions in the adult retina.

\section{Introduction}

Gap junctions are frequently observed in the adult retina (Massey et al., 2003; Bloomfield and Völgyi, 2009). It has been widely assumed that gap junctions may function as passive electrotonic pathways in the retina. For example, photoreceptor couplings contribute to signal averaging (DeVries et al., 2002), horizontal cell couplings to regulation of the receptive field size (Schwartz, 1975; Bloomfield et al., 1995), and amacrine cell couplings to synchronization of membrane potential fluctuations (Veruki and Hartveit, 2002a). Furthermore, it has been shown that heterogeneous gap junctions between rod bipolar cells and AII amacrine cells transmit rod signals to cone pathways (Nelson, 1977; Veruki and Hartveit, 2002b; Münch et al., 2009). Except for gap junctions between horizontal cells (McMahon and Mattson, 1996), gap junctions in the retina are relatively small in conductance and behave as a low-pass filter (DeVries et al., 2002; Veruki and Hartveit, 2002a,b; Zhang and $\mathrm{Wu}, 2005)$. Thus, the fast and transient $\mathrm{Na}^{+}$spike generated in an AII amacrine cell evokes a decayed electrotonic depolarization in neighboring electrically

Received March 29, 2010; revised May 19, 2010; accepted May 26, 2010.

This work was supported by Japan Society for the Promotion of Science, Grant-in-Aid for Scientific Research (KAKENHI) (18300132 and 21300148) and by The Ministry of Education, Culture, Sports, Science, and Technology KAKENHI (20019017) to M.T. We thank M. Gangi and H. Hoshi for performing immunohistochemical experiments.

Correspondence should be addressed to Masao Tachibana, Department of Psychology, Graduate School of Humanities and Sociology, The University of Tokyo, 7-3-1 Hongo, Bunkyo-ku, Tokyo 113-0033, Japan. E-mail: tchbn2ms@l.u-tokyo.ac.jp.

DOI:10.1523/JNEUROSCI.1590-10.2010

Copyright $\odot 2010$ the authors $\quad 0270-6474 / 10 / 309260-11 \$ 15.00 / 0$ coupled AII amacrine cells, but such depolarization is not strong enough to trigger $\mathrm{Na}^{+}$spikes (Veruki and Hartveit, 2002a).

Bipolar cells (BCs) are second-order neurons in the retina, and play key roles in visual information processing. Although existence of gap junctions between BCs was reported more than two decades ago (Kujiraoka and Saito, 1986), their properties and functional roles have not yet been elucidated. It is generally accepted that retinal BCs respond to light stimulation with graded potentials (Werblin and Dowling, 1969; Kaneko, 1973). However, recent studies show that some types of BCs have the ability to generate $\mathrm{Ca}^{2+}$ and/or $\mathrm{Na}^{+}$spikes $\left[\mathrm{Ca}^{2+}\right.$ spikes: Burrone and Lagnado (1997), Zenisek and Matthews (1998), Protti et al. (2000), Hull et al. (2006), Palmer (2006), and Hu et al. (2009); $\mathrm{Na}^{+}$spikes: $\mathrm{Ma}$ et al. (2005); $\mathrm{Ca}^{2+}$ and $\mathrm{Na}^{+}$spikes: $\mathrm{Ma}$ and Pan (2003)]. As $\mathrm{Ca}^{2+}$ and/or $\mathrm{Na}^{+}$spikes in BCs are much slower in time course than $\mathrm{Na}^{+}$spikes in amacrine cells, it is intriguing to know how the electrically coupled BCs with such active membrane properties behave in the retina.

In the present study, applying dual whole-cell clamp techniques to the adult goldfish retina, we examined the properties of gap junctions between ON-type bipolar cells with a giant axon terminal (Mb1-BCs) and their contribution to signal transmission from Mb1-BCs to postsynaptic ganglion cells (GCs). We show that gap junctions are located at the distal dendrites of Mb1-BCs and behave as a low-pass filter. Furthermore, we find that the electrically coupled Mb1-BC network can spread $\mathrm{Ca}^{2+}$ spikes through gap junctions with a time lag, resulting in a long-lasting EPSC in the GC. Our results suggest that gap junctions between bipolar cells may play a key role in lateral interactions in the adult retina. 


\section{Materials and Methods}

Preparations. Slice and whole-mount preparations were obtained from goldfish (Carassius auratus; body length, $8-15 \mathrm{~cm}$ ) retinas. Experiments were performed in accordance with "A Manual for the Conduct of Animal Experiments in The University of Tokyo" and "Guiding Principles for the Care and Use of Animals in the Field of Physiological Sciences," The Physiological Society of Japan.

The procedures for preparing goldfish retinal slices were nearly identical to those reported previously in amphibian retinas (Matsui et al., 1998; Hosoi et al., 2005). Briefly, a goldfish was double pithed, and its eyes were enucleated. Under the stereomicroscope, the cornea and lens were ablated. The eyecup was cut into a few pieces and the ganglion cell layer side of the retina was attached to a piece of filter paper (Type AA, Millipore). After removing the sclera and the pigment epithelium, the retina attached to the filter paper was placed in a humidified box for $\sim 10$ min, during which time most of the vitreous humor was absorbed into the filter paper. Then, the retina attached to the filter paper was cut into $\sim 150 \mu \mathrm{m}$ sections with a hand-made slicer. The retinal slices were transferred to a recording chamber and held down by fine nylon threads affixed to a platinum horseshoe.

The procedures for making whole-mount preparations were similar to those described previously (Arai et al., 2004). Briefly, a goldfish was deeply anesthetized with ethyl 3-aminobenzoate methanesulfonate (1 $\mathrm{g} / \mathrm{L}$ MS-222, Sigma). Collagenase and hyaluronidase $(5 \mathrm{mg} / \mathrm{ml}$ each, Sigma) dissolved in the control external solution was injected into eyes $(\sim 200 \mu \mathrm{l} /$ eye $)$ to dissolve vitreous humor. One to three hours after injection, the goldfish was double pithed, and its eyes were enucleated. Under the stereomicroscope, the retina was isolated from the pigment epithelium in the oxygenated control solution. Then the isolated retina was transferred to the recording chamber and fixed with the platinum horseshoe described above.

The recording chamber was mounted on the stage of a microscope equipped with IR differential interference optics (Eclipse E600FN, Nikon) and an IR-CCD camera (C2400-79H, Hamamatsu Photonics). Recordings were performed in a light-tight Faraday cage at room temperature $\left(\sim 25^{\circ} \mathrm{C}\right)$.

Extracellular solutions. The control solution contained (in mM) 106 $\mathrm{NaCl}, 10$ D-glucose, $2.6 \mathrm{KCl}, 28 \mathrm{NaHCO}_{3}, 2.5 \mathrm{CaCl}_{2}, 1 \mathrm{MgCl}_{2}$, and $2 \mathrm{mg} / \mathrm{L}$ phenol red $(273 \mathrm{mOsm})$. The solution was continuously bubbled with $95 \% \mathrm{O}_{2} / 5 \% \mathrm{CO}_{2}$ to keep the $\mathrm{pH}$ at 7.4 and was fed into the recording chamber by a peristaltic pump at a rate of $1.6 \mathrm{ml} / \mathrm{min}$. In some experiments, $\mathrm{CaCl}_{2}$ and $\mathrm{MgCl}_{2}$ were replaced with equimolar $\mathrm{CoCl}_{2}$ to block chemical synaptic transmission.

Pharmacological agents dissolved in the control solution were bath-applied. We purchased (AS)-rel-a- $(2 R)$-2-piperidinyl-2,8-bis (trifluoromethyl)-4-quinolinemethanol monohydrochloride (mefloquine), picrotoxin, and strychnine from Sigma, L-(+)-2-amino-4-phosphonobutyric acid (L-AP4), D-(-)-2-amino-5-phosphonopentanoic acid (D-AP5) and 2,3-dioxo-6-nitro-1,2,3,4-tetrahydrobenzo[f] quinoxaline7-sulfonamide (NBQX) from Tocris Bioscience, and tetrodotoxin (TTX) from Wako. Mefloquine, picrotoxin, and NBQX were dissolved in dimethyl sulfoxide (DMSO) for stock solutions. The final concentration of DMSO dissolved in the control solution was always kept $<0.1 \%(\mathrm{v} / \mathrm{v})$.

Whole-cell recordings. Two kinds of pipette solutions were used in the present study. The $\mathrm{K}^{+}$-based solution contained (in $\mathrm{mM}$ ) $10 \mathrm{KCl}, 128$ K-gluconate, 10 HEPES, 0.5 EGTA, $0.05 \mathrm{CaCl}_{2}, 2 \mathrm{MgCl}_{2}, 0.5 \mathrm{Na}_{3} \mathrm{GTP}, 5$ $\mathrm{Na}_{2}$ ATP, and $0.08 \%$ Lucifer yellow dipotassium salt (269 mOsm). The $\mathrm{pH}$ was titrated to 7.4 with $\mathrm{KOH}$. The $\mathrm{Cs}^{+}$-based solution contained (in mM) $115 \mathrm{CsMeSO}_{3}, 10$ HEPES, 0.5 EGTA, $0.05 \mathrm{CaCl}_{2}, 2 \mathrm{MgCl}_{2}, 10 \mathrm{TEA}-$ $\mathrm{Cl}, 0.5 \mathrm{Na}_{3} \mathrm{GTP}, 5 \mathrm{Na}_{2} \mathrm{ATP}$, and $0.08 \%$ Lucifer yellow dipotassium salt (270 mOsm). The $\mathrm{pH}$ was titrated to 7.4 with $\mathrm{CsOH}$.

Patch pipettes were pulled with a horizontal puller (P97, Sutter Instruments). The electrode resistance of the pipette filled with either pipette solution was $8 \sim 12 \mathrm{M} \Omega$ in the control external solution.

Recordings were performed with EPC-10/3 (HEKA) controlled by the PatchMaster software (v2.15, HEKA). The fast capacitance components were mostly cancelled by the circuit of the amplifier. However, the slow capacitance components of Mb1-BC were not well cancelled mainly be- cause of the electrical coupling among Mb1-BCs. Current records were low-pass filtered at $2.9 \mathrm{kHz}$ and the sampling frequency was in the range of $10-50 \mathrm{kHz}$.

Cell identification. Cells were whole-cell clamped with a patch pipette filled with the solution containing Lucifer yellow. Their morphology was visualized under epifluorescence illumination after recording. Fluorescent images were acquired by the IR-CCD camera and saved in the memory of a computer.

The Mb1-BC could be identified by its characteristic morphology (Sherry and Yazulla, 1993). The large axon terminal ( $\sim 10 \mu \mathrm{m}$ in diameter) could be easily found in the proximal inner plexiform layer (IPL), sublamina b, where ON-type neurons make synapses (Famiglietti et al., 1977; Palmer et al., 2003a). A recording pipette was usually positioned at the axon terminal of Mb1-BCs. When the $\mathrm{K}^{+}$-based pipette solution was used, the resting membrane potential of Mb1-BCs was $-37.8 \pm 0.92 \mathrm{mV}$ $(n=25)$ under dark-adapted conditions and $-39.1 \pm 0.55 \mathrm{mV}(n=23)$ under light-adapted conditions. There was no significant difference between two conditions ( $p=0.23$, unpaired $t$ test). For current-clamp recordings from Mb1-BCs, a constant current $(<-50 \mathrm{pA})$ was usually injected into each cell to keep the membrane potential at approximately $-40 \mathrm{mV}$.

In some experiments, we recorded from the isolated giant axon terminal of $\mathrm{Mb} 1-\mathrm{BC}$ or from the truncated Mb1-BC without axon terminal. During the slicing procedure, the axon of Mb1-BC was incidentally severed (Palmer et al., 2003b). The isolated giant axon terminal of Mb1-BC could be easily discriminated from the soma of ganglion cells; the former was located in the IPL, and the sustained $I_{\mathrm{Ca}}$ or $\mathrm{Ca}^{2+}$ spikes could be activated by depolarization, whereas the latter was located in the ganglion cell layer, and the transient $\mathrm{Na}^{+}$current or $\mathrm{Na}^{+}$spikes could be generated (von Gersdorff and Matthews, 1994). The truncated Mb1-BC without axon terminal could be identified by its dendritic arborization, and by its shape, location, and size of the soma (Sherry and Yazulla, 1993).

We recorded from the GC, the soma of which was located in the vicinity of the axon terminal of the whole-cell clamped Mb1-BC. Light responses were recorded from some GCs, which could be classified into the ON-OFF transient type $(n=3)$, the ON transient type $(n=4)$, and the ON sustained type $(n=2)$.

Light adaptation level. Either dark-adapted or light-adapted retina was used for experiments. Under dark-adapted conditions, goldfish was dark adapted for at least $1 \mathrm{~h}$ before making preparations. For the slice preparation, the eye was dissected under the stereomicroscope equipped with infrared (IR) LED illumination and IR converters (Night Viewer C5100, Hamamatsu Photonics). Other procedures were performed under dim red light. Under light-adapted conditions, all experimental procedures were conducted under room light.

Tracer coupling experiments. Using the whole-mount preparation, we positioned the tip of a patch pipette containing $5 \%$ Neurobiotin at the axon terminal of an $\mathrm{Mb} 1-\mathrm{BC}$ and whole-cell clamped for $>30 \mathrm{~min}$. After recording, the patch pipette was removed carefully and the retinal tissue was incubated in the fixative (10\% formalin, $15 \%$ picric acid in $0.1 \mathrm{M}$ PBS) for $30 \mathrm{~min}$ at a room temperature. Then, the tissue was rinsed with $0.1 \mathrm{M}$ PBS, and left in the dark for $>1 \mathrm{~d}$ at $4^{\circ} \mathrm{C}$. The tissue was incubated in $0.1 \mathrm{M}$ PBS containing either $1 \%$ streptavidin-conjugated Cy3 (Jackson ImmunoResearch) or $1 \%$ streptavidin-conjugated Alexa488 (Invitrogen) and $0.1 \%$ Triton-X for $4 \mathrm{~d}$. After incubation, the tissue was rinsed with $0.1 \mathrm{M}$ PBS, and then it was placed on an aminopropylsilane-coated glass and enclosed with Pristine Mount (Falma). The preparation was examined with confocal laser-scanning microscopes (FluoView FV1000, Olympus; A1, Nikon, excitation wavelength: $543 \mathrm{~nm}$ for Cy3, $488 \mathrm{~nm}$ for Alexa488).

Immunohistochemical experiments. After fixation with $4 \%$ paraformaldehyde in $0.1 \mathrm{M}$ PBS, the isolated retinas were rinsed with $0.1 \mathrm{M} \mathrm{PBS}$, and then blocked by using 3\% BSA (Sigma) and $0.3 \%$ Triton X-100 in $0.1 \mathrm{M}$ PBS for $90 \mathrm{~min}$ at room temperature. The retinas were incubated with primary antibodies in $0.1 \mathrm{M}$ PBS with $0.3 \%$ Triton X-100 for $7 \mathrm{~d}$ at $4^{\circ} \mathrm{C}$. Then, the retinas were rinsed several times in $0.1 \mathrm{M}$ PBS and reincubated in the secondary antibody overnight at $4^{\circ} \mathrm{C}$. The primary antibodies used were rabbit anti-pPKC $\alpha$ (Santa Cruz Biotechnology; 1:500) and mouse anti-Cx35/36 (Millipore; 1:500). The secondary antibodies used were 
donkey anti-rabbit Alexa488 (Invitrogen) and donkey anti-mouse IgG $(\mathrm{H}+\mathrm{L}) \mathrm{Cy} 3$ (Jackson ImmunoResearch).

Data analysis. Data were analyzed using Igor Pro (v4.0.6, WaveMetrics) and Excel 2000 (Microsoft). The coupling conductance $\left(G_{\mathrm{gj}}\right)$ was obtained either from the slope of the transjunctional current $\left(I_{\mathrm{gj}}\right)$-voltage difference $\left(V_{\mathrm{dif}}\right)$ relation in the range of -40 to $+150 \mathrm{mV}$ or from the value of the transjunctional current divided by the applied fixed voltage difference $(40 \mathrm{mV})$, respectively. The values obtained by either procedure were not statistically different ( $p=0.44$, paired $t$ test, $n=6$ ).

To examine the frequency characteristics of gap junctions, a series of sinusoidal currents with various frequencies $(0.1 \sim 100 \mathrm{~Hz})$ was injected into one cell of the pair and the voltage responses were recorded from both cells under current clamp. To exclude the influence of voltage- and $\mathrm{Ca}^{2+}$-activated membrane currents of Mb1-BCs, the Cs ${ }^{+}$-based pipette solution was used, and external $\mathrm{CaCl}_{2}$ and $\mathrm{MgCl}_{2}$ were replaced with equimolar $\mathrm{CoCl}_{2}$. Each voltage response was fitted with a sinusoidal curve to calculate the response amplitude and phase shift by the equation $V(t)=V_{0}+A \times \sin (F \times t+P)$, where $V(t), V_{0}, A, F, t$, and $P$ are the voltage response at time $t$, baseline voltage, response amplitude, stimulus frequency, time, and phase, respectively.

Statistical analyses were performed with Student's two-tailed $t$ tests and ANOVA with a level of significance of $p<0.05$. Data were presented as means \pm SEM.

\section{Results}

\section{Couplings between Mb1-BCs}

To confirm the existence of gap junctions between Mb1-BCs in the goldfish retina, we examined the tracer coupling by introducing Neurobiotin through a recording pipette into the giant axon terminal of an Mb1-BC in the whole-mount preparation. Not only the recorded $\mathrm{Mb} 1-\mathrm{BC}$ but also some surrounding cells were Neurobiotin positive (Fig. 1A). Confocal laser-scanning microscopy revealed that the somata of tracer-coupled cells were similar in shape and located at the same level of the inner nuclear layer (INL) (Fig. 1 $\mathrm{A}, \mathrm{INL}$ ) and that a single axon extruded from each soma was connected to a giant bulbous axon terminal at the sublamina b of the IPL (Fig. 1A, IPL). These observations indicate that the tracer-coupled cells are Mb1-BCs. The number of the tracer-coupled surrounding Mb1-BCs was in the range of 2-7 $($ mode $=6$, mean $\pm \mathrm{SEM}=4.91 \pm 0.41, n=8)$.

To examine the electrical coupling between Mb1-BCs, we applied paired whole-cell clamp techniques to the slice preparation. Lucifer yellow was introduced into each Mb1-BC through recording pipettes, but we never observed tracer-coupled neighboring cells (Fig. $1 \mathrm{~B}$ ), probably because Lucifer yellow has negative charges and larger molecular weight than Neurobiotin (Harris, 2001). When a hyperpolarizing voltage pulse (from -60 to $-100 \mathrm{mV}$ ) was applied to the $\mathrm{BC}(1)$, an inward leak current was induced in the $\mathrm{BC}(1)$ and an outward current was evoked in the $\mathrm{BC}(2)$ voltage clamped at $-60 \mathrm{mV}$ (Fig. 1C, left). The signal transmission was bidirectional ( $n=57$ pairs). Application of mefloquine (MFQ), a specific blocker of connexin 36 and 50 (Cx36/50) (Cruikshank et al., 2004), reduced the inward leak current in the hyperpolarized cell and suppressed the outward current in its counterpart (Fig. 1D). This treatment decreased the gap junction conductance $\left(G_{\mathrm{g}}\right)$, which is defined as the transjunctional current divided by the voltage difference $\left(V_{\mathrm{dif}}\right)$ between paired cells, to $9.6 \pm 3.7 \%$ of control ( $n=4$ pairs, $p<0.01$, paired $t$ test). On the other hand, application of $\mathrm{Co}^{2+}$, a blocker of chemical synaptic transmission, did not suppress the signal transmission between Mb1-BCs $\left(G_{\mathrm{gj}}: 112.7 \pm 6.3 \%\right.$ of control, $n=13$ pairs, $p=0.07$, paired $t$ test). These results show that Mb1-BCs in the goldfish retina are electrically coupled through gap junctions.

It has been reported that gap junctions between bipolar cells are formed at the dendrites [carp Mb-BCs, Kujiraoka and Saito
(1986); cat cone-BCs, Kolb (1979)], at the axon terminals [goldfish Ma-BCs, Marc et al. (1988); Macaque cone-BCs, Jacoby and Marshak (2000)], or at both the dendrites and axon terminals [carp and black bass OFF-type BCs (Umino et al., 1994)]. To examine electrophysiologically the subcellular location of gap junctions between goldfish Mb1-BCs, we performed two sets of paired recordings. First, we recorded from a pair of an isolated axon terminal $[\mathrm{AT}(1)]$ of Mb1-BC and an intact Mb1-BC [BC(2)] (Fig. 1E) (see also Materials and Methods). Neither the $\mathrm{AT}(1)$ nor the $\mathrm{BC}(2)$ evoked the transjunctional outward current to a hyperpolarizing pulse applied to the counterpart of the pair (Fig. $1 F)(n=7$ pairs). Second, we recorded from a pair of a truncated Mb1-BC without axon terminal [TC(1)] and an intact Mb1-BC [BC(2)] (Fig. 1G) or a pair of truncated Mb1-BCs. Application of a hyperpolarizing voltage pulse to one cell of the pair could evoke the transjunctional outward current in its counterpart (Fig. $1 H)(n=6$ pairs), and the coupling conductance was not significantly different from that obtained from pairs of intact Mb1-BCs (pairs of truncated Mb1-BC and intact/truncated Mb1-BC: $0.70 \pm 0.18 \mathrm{nS}, n=6$, pairs of intact Mb1-BCs: $0.72 \pm$ $0.38, n=4 ; p=0.96$, paired $t$ test).

The electrical coupling between Mb1-BCs could be blocked by MFQ (Fig. 1D), suggesting that the gap junctions may consist of Cx36/50 (Cruikshank et al., 2004). It has been reported that Mb1$\mathrm{BCs}$ and some cone $\mathrm{ON} \mathrm{BCs}$ are immunoreactive to anti-PKC $\alpha$ antibody (Negishi et al., 1988; Suzuki and Kaneko, 1991). Thus, double immunohistochemical labeling was performed by using anti-PKC $\alpha$ and anti-Cx35/36 antibodies. We found an array of the PKC-immunolabeled Mb1-BCs in addition to the faintly immunolabeled small BCs (supplemental Fig. $1 \mathrm{~A}$, available at www. jneurosci.org as supplemental material). The distal dendrites of Mb1-BC seemed to be in contact with those of surrounding Mb1BCs (supplemental Fig. $1 B$, available at www.jneurosci.org as supplemental material), and some Cx35/36-immunoreactive puncta coincided with the contacted dendritic processes of Mb1BCs (supplemental Fig. 1C, available at www.jneurosci.org as supplemental material). The PKC-immunolabeled Mb1-BC had the large axon terminal with some telodendria (supplemental Fig. $1 D$, available at www.jneurosci.org as supplemental material). We examined 276 PKC-immunolabeled axon terminals of Mb1BCs from two retinas with a confocal laser-scanning microscope, and found that 26 pairs of axon terminals seemed to make contact with each other through a single pair of telodendria. However, we did not observe Cx35/36-immunoreactive puncta coincident with the seemingly contacted telodendria of Mb1-BCs (supplemental Fig. $1 E$, available at www.jneurosci.org as supplemental material). These electrophysiological and immunohistochemical results indicate that gap junctions are mostly located at the distal dendrites of Mb1-BCs.

\section{Properties of gap junctions}

Paired recordings were performed to examine the voltage dependence of $G_{\mathrm{gj}}$ between neighboring Mb1-BCs. Recording pipettes were positioned at the axon terminals and both cells were voltage clamped at $-60 \mathrm{mV}$. A series of voltage pulses was applied to one cell of the pair, and the induced currents were recorded from both cells (Fig. 2A). The current could pass bidirectionally through gap junctions. The relation between the transjunctional current $\left(I_{\mathrm{gj}}\right)$ and the voltage difference $\left(V_{\mathrm{dif}}\right)$ was linear in the range of -40 to $+150 \mathrm{mV}$ (Fig. $2 \mathrm{~B}$ ). The $G_{\mathrm{gj}}$ calculated from the slope of the $I_{\mathrm{gj}}-V_{\text {dif }}$ relation was almost identical for both directions (Fig. $2 B, C)(n=16$ pairs, $p=0.88$, paired $t$ test $)$, and it was $0.80 \pm$ $0.08 \mathrm{nS}$ ( $n=16$ pairs). Neither voltage dependence nor rectifica- 
A

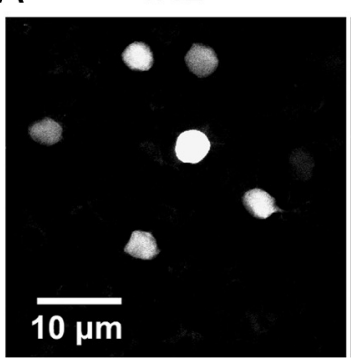

C

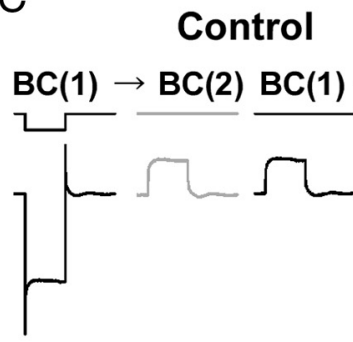

E

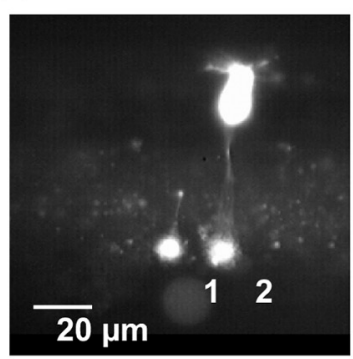

G

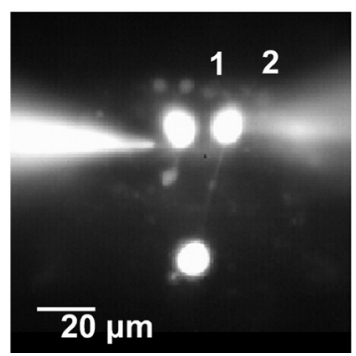

IPL
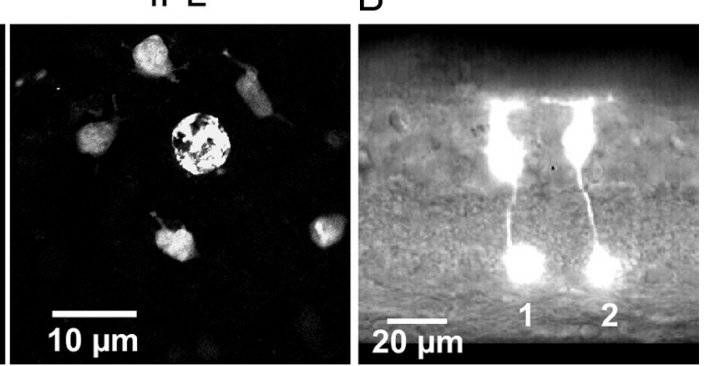

MFQ

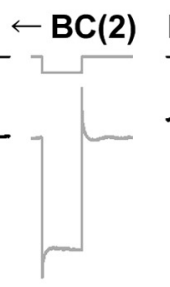

$\mathrm{BC}(1) \rightarrow \mathrm{BC}(2) \quad \mathrm{BC}(1) \leftarrow \mathrm{BC}(2)$
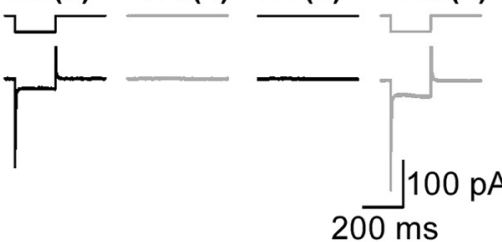

$200 \mathrm{~ms}$

$\mathrm{F}$
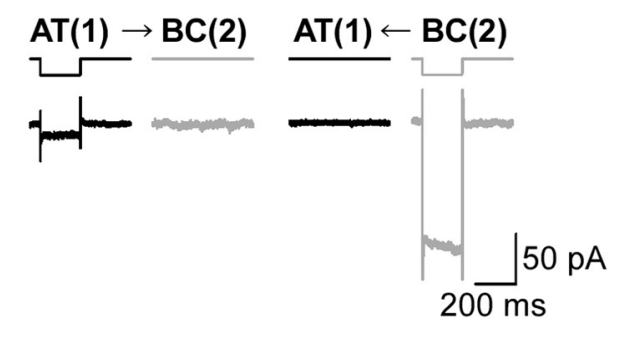

$\mathrm{H}$
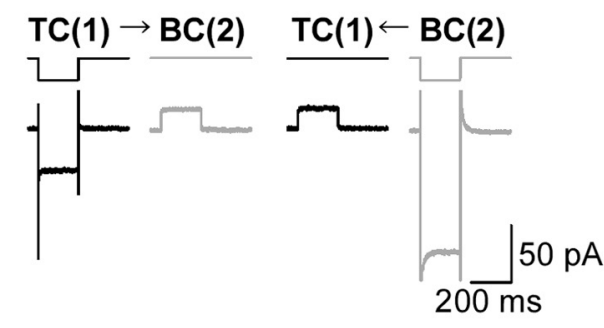

Figure 1. Electrical coupling between Mb1-BCs.A, Tracer coupling among Mb1-BCs. Neurobiotin was introduced through a recording pipette into the axon terminal of an Mb1-BC in the light-adapted, whole-mount preparation. After fixation, Neurobiotin was visualized by streptavidin-conjugated Alexa488, and then the preparation was observed under confocal microscope. The focal plane was at the level of the INL (left) and at the IPL (right). $\boldsymbol{B}$, Fluorescence micrograph of two neighboring intact Mb1-BCs in the slice preparation. Each cell was filled with Lucifer yellow through a recording pipette. $C$, Recordings from a neighboring pair of intact Mb1- $B C S[B C(1)$ and $B C(2)$ : different from $B$ ] in the light-adapted retina. Both cells were voltage clamped at $-60 \mathrm{mV}$. Hyperpolarization (to $-100 \mathrm{mV}$ for $200 \mathrm{~ms}$ ) of one cell of the pair evoked a transjunctional outward current in the other. The control external solution and the $C{ }^{+}{ }^{+}$-based pipette solution were used. $D$, Recordings from the same pair shown in $\boldsymbol{C}$ after $>30$ min treatment with MFQ (10 $\mu \mathrm{m})$. $\boldsymbol{E}$, Fluorescence micrograph. 1, An isolated giant axon terminal of Mb1-BC [AT(1)].2, An intact Mb1-BC [BC(2)]. F, Recordings from the pair of AT(1) and BC(2) shown in $\boldsymbol{E}$. Both were voltage clamped at $-60 \mathrm{mV}$. Hyperpolarization (to $-100 \mathrm{mV}$ for $200 \mathrm{~ms}$ ) of one cell of the pair did not evoke any response in the other cell. The control external solution and the $\mathrm{K}^{+}$-based pipette solution were used. The traces shown are from the dark-adapted condition. G, Fluorescence micrograph. 1, A truncated Mb1-BC without axon terminal $[T C(1)]$.2, An intactMb1-BC $[B C(2)]$. $\boldsymbol{H}$, Recordings from the pair of $\mathrm{TC}(1)$ and $B C(2)$ shown in $\mathbf{G}$. Both were voltage clamped at $-60 \mathrm{mV}$. Hyperpolarization (to $-100 \mathrm{mV}$ for $200 \mathrm{~ms}$ ) of one cell of the pair evoked a transjunctional outward current in the other cell. The control external solution and the $\mathrm{K}^{+}$-based pipette solution were used. The traces shown are from the dark-adapted condition.

tion was observed in this range of voltage differences. There was no indication of the time-dependent change of $G_{\mathrm{gj}}$ because application of a series of long (10 s in duration) voltage pulses into one of the pair evoked steady current responses in the counterpart ( $n=5$ pairs, data not shown).
We also examined the temporal filtering property of gap junctions between neighboring Mb1-BCs. A series of sinusoidal currents was injected into one of the pair, and the evoked responses were recorded from both cells under current clamp (Fig. 2D). In this experiment, the voltage- and $\mathrm{Ca}^{2+}$-dependent $\mathrm{K}^{+}$currents and the voltage-dependent $\mathrm{Ca}^{2+}$ current were blocked by intracellular $\mathrm{Cs}^{+}$and extracellular $\mathrm{Co}^{2+}$, respectively. The evoked voltage response could be fitted with a single sinusoidal curve, and both the coupling ratio and the phase shift were calculated. As shown in Figure 2E, the coupling ratio was maximal around 2 $\mathrm{Hz}$ and the cutoff frequency $(-3 \mathrm{~dB}$ from the maximal power) was $\sim 10 \mathrm{~Hz}$. These results indicate that the electrical coupling between Mb1-BCs behaves as a low-pass filter.

\section{Spread of $\mathrm{Ca}^{2+}$ spikes through gap junctions}

Retinal bipolar cells respond to light stimulation with graded potentials (Werblin and Dowling, 1969; Kaneko, 1973). However, recent studies have shown that bipolar cells have the ability to generate $\mathrm{Ca}^{2+}$ and/or $\mathrm{Na}^{+}$spikes $\left[\mathrm{Ca}^{2+}\right.$ spikes: Burrone and Lagnado (1997), Zenisek and Matthews (1998), Protti et al. (2000), Hull et al. (2006), Palmer (2006), and $\mathrm{Hu}$ et al. (2009); $\mathrm{Na}^{+}$ spikes: $\mathrm{Ma}$ et al. (2005); $\mathrm{Ca}^{2+}$ and $\mathrm{Na}^{+}$ spikes: Ma and Pan (2003)]. Goldfish Mb1BCs do not express $\mathrm{Na}^{+}$channels (Zenisek et al., 2001), but they can generate $\mathrm{Ca}^{2+}$ spikes in response to depolarizing current injection [the acutely dissociated Mb1-BCs: Burrone and Lagnado (1997) and Zenisek and Matthews (1998); the isolated axon terminals in the slice preparation: Hull et al. (2006) and Palmer (2006)] or to light stimulation, especially under dark-adapted conditions (Protti et al., 2000). It is interesting to ask whether $\mathrm{Ca}^{2+}$ spikes can spread through gap junctions between Mb1-BCs.

First, we examined whether the intact Mb1-BCs in the dark-adapted retinal slice preparation could generate $\mathrm{Ca}^{2+}$ spikes. A series of current pulses was applied to a current-clamped Mb1-BC (Fig. 3A, left upper traces). Injection of a large depolarizing pulse evoked a transient response, which decayed to a plateau slowly (Fig. $3 A$, left lower traces). The transient response did not seem to be an "all-ornone" event that was reported by Protti et al. (2000) (light-evoked $\mathrm{Ca}^{2+}$ spikes recorded from Mb1-BCs in the dark-adapted retina) and Palmer (2006) (depolarizationevoked $\mathrm{Ca}^{2+}$ spikes recorded from the isolated axon terminal of $\mathrm{Mb} 1-\mathrm{BCs})$. However, as the intensity of the injected current was increased, the amplitude of both transient and plateau responses 

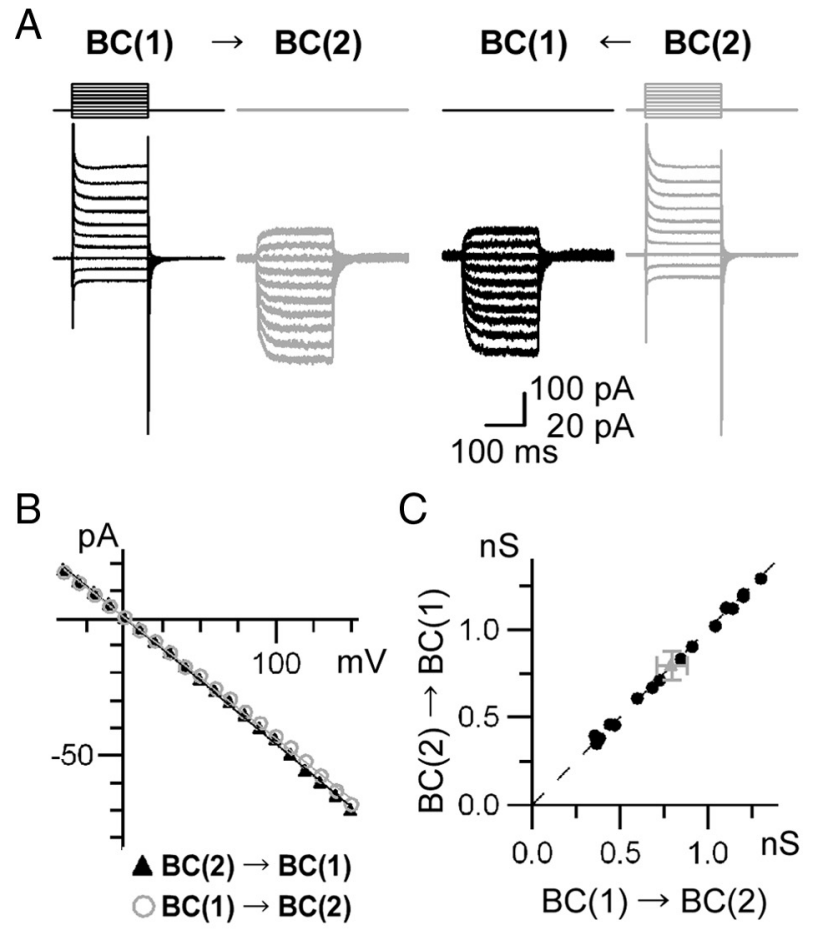

D

$\mathrm{E}$

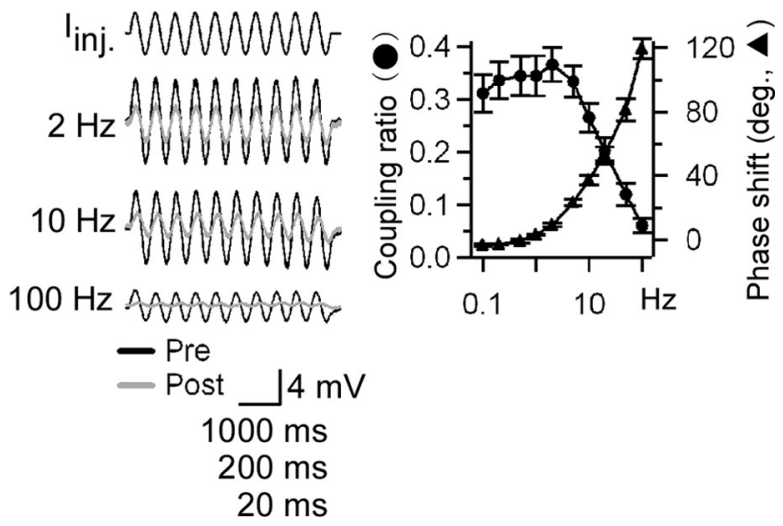

Figure 2. Properties of gap junctions. $A-C$, Voltage dependence and rectification of the gap junction conductance. $\boldsymbol{A}$, Recordings from a pair of intact $\mathrm{Mb} 1-\mathrm{BC}$ in the light-adapted slice preparation. Both cells were voltage clamped at $-60 \mathrm{mV}$. Voltage steps ( $10 \mathrm{mV}$ increment from -100 to $+90 \mathrm{mV}$ for $200 \mathrm{~ms}$ ) were applied to one cell of the pair and the currents were recorded from both cells. The $\mathrm{Co}^{2+}$ extracellular solution and the $\mathrm{Cs}^{+}$-based pipette solution were used. $\boldsymbol{B}, I_{\mathrm{gj}}-V_{\text {dif }}$ relations obtained from $\boldsymbol{A}$. The amplitude of the transjunctional current $\left(I_{\mathrm{gj}}\right)$ was plotted against the voltage difference $\left(V_{\text {dif }}\right)$ between paired cells. $C$, Pooled data of the gap junction conductance $G_{\mathrm{gj}}\left(n=16\right.$ pairs). $G_{\mathrm{gj}}$ was calculated from the slope of $I_{\mathrm{gj}}-V_{\mathrm{dif}}$ relations as shown in $\boldsymbol{B}$. Raw (black) and averaged (gray) data are shown. $\boldsymbol{D}$, $\boldsymbol{E}$, Temporal filtering property of the gap junctions. $D$, Examples of voltage responses evoked by sinusoidal current injection ( $I_{\text {in: }}$ : peak-to-peak $20 \mathrm{pA}$ ) at various frequencies. Responses from presynaptic (Pre; black) and postsynaptic (Post; gray) cells under current clamp were superimposed. The $\mathrm{C}^{2+}$ extracellular solution and the $\mathrm{Cs}^{+}$-based pipette solution were used. The traces shown are from the light-adapted condition. $E$, Coupling ratio and phase shift. Each symbol represents the mean \pm SEM ( $n=4-5$ pairs).

deviated from the linear $V-I$ relation that would be unexpected from the cells without active membrane properties (Fig. $3 A$, right). For large current injections, the transient and plateau responses manifested as a prominent supralinearity and sublinearity, respectively (Fig. $3 A$, right arrows). Similar nonlinear properties were observed in 60 cells $(\sim 60 \%$ of successfully recorded Mb1-BCs). Extracellular application of $\mathrm{Co}^{2+}$ suppressed
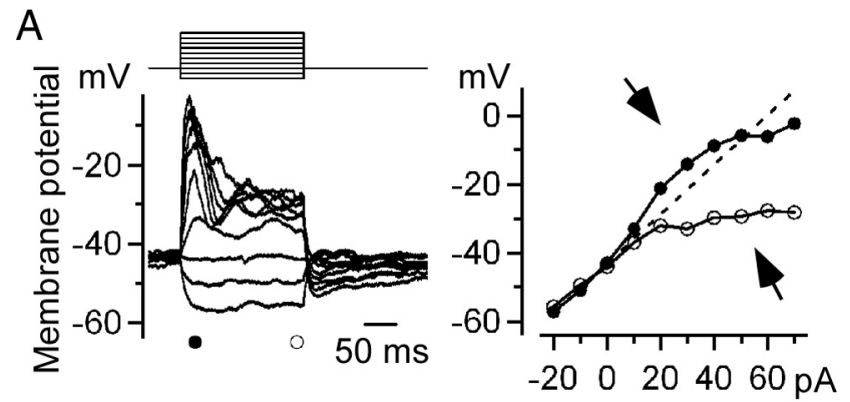

B
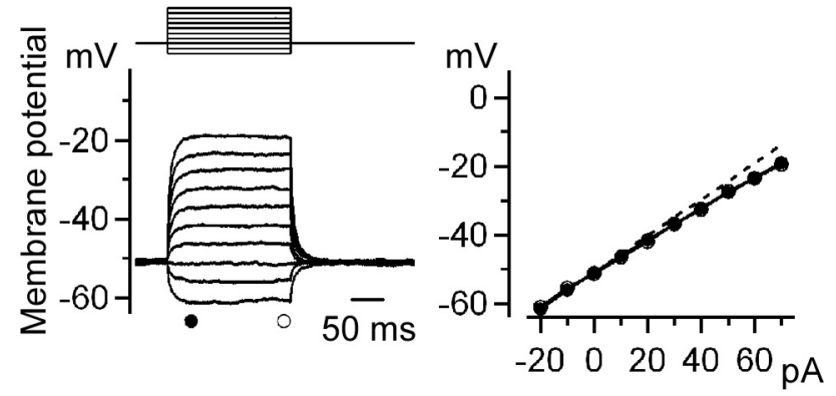

Figure 3. $\mathrm{Ca}^{2+}$ spikes generated by current injection. $A$, Left, Membrane potential changes induced by current injection. A series of current pulses ( $10 \mathrm{pA}$ increment from -20 to $+70 \mathrm{pA}$ for $200 \mathrm{~ms}$ ) was injected into a current-clamped Mb1-BC in the dark-adapted retina. The control external solution and the $\mathrm{K}^{+}$-based pipette solution were used. Right, $\mathrm{V}$-I relations obtained from the left panel. The amplitude of the peak (filled circles) and plateau (open circles) potentials were plotted against the intensity of the injected current. The straight line was extrapolated from the relation between the hyperpolarizing currents and the responses (broken line). Deviation from the straight line was observed for large current injection (arrows). B, Membrane potential changes induced by current injection in the presence of $\mathrm{CO}^{2+}$. Data were obtained from the same cell shown in $\boldsymbol{A}$.

the active membrane properties and the $V-I$ relation became almost linear (Fig. 3B). These results indicate that the transient and plateau responses are induced by the interplay between the $\mathrm{Ca}^{2+}$ current and the $\mathrm{Ca}^{2+}$-activated currents (Kaneko and Tachibana, 1985; Okada et al., 1995; Burrone and Lagnado, 1997; Protti et al., 2000). It is obvious that Mb1-BCs have the ability to generate $\mathrm{Ca}^{2+}$-dependent transient responses, which will be described simply as $\mathrm{Ca}^{2+}$ spikes below.

Second, we examined whether $\mathrm{Ca}^{2+}$ spikes could be transmitted through gap junctions. Paired recordings were made from neighboring Mb1-BCs. Hyperpolarizing current was constantly injected into both $\mathrm{BC}(1)$ and $\mathrm{BC}(2)$ to maintain their membrane potentials $\left(V_{\mathrm{m}}\right)$ at approximately $-60 \mathrm{mV}$, where the $\mathrm{Ca}^{2+}$ current and the $\mathrm{Ca}^{2+}$-dependent currents were hardly activated. The presynaptic $\mathrm{BC}(1)$ response $\left(V_{\text {pre }}\right)$ induced by depolarizing current injection $\left(I_{\text {inj }}\right)$ seemed to be transmitted passively to the postsynaptic $\mathrm{BC}(2)$ through gap junctions (Fig. 4A). The postsynaptic $\mathrm{BC}(2)$ response $\left(V_{\text {post }}\right)$ was smaller in amplitude than $V_{\text {pre }}$. The time course of $V_{\text {post }}$ was delayed slightly because of the low-pass filtering property of gap junctions (Fig. 2E). This was true even when a $\mathrm{Ca}^{2+}$ spike was generated in the $\mathrm{BC}(1)$ (Fig. $4 A$, right). When the $V_{\mathrm{m}}$ of both BCs was set to a physiological value (approximately $-40 \mathrm{mV}$; see Materials and Methods), large current injection induced a $\mathrm{Ca}^{2+}$ spike in the $\mathrm{BC}(1)$, which in turn triggered a transient response with an undershoot followed by a small plateau in the $\mathrm{BC}(2)$ (Fig. $4 B$ ). The waveform was so different between $V_{\text {pre }}$ and $V_{\text {post }}$ (Fig. $4 B$, right) that $V_{\text {post }}$ could not be explained by a passive electrotonic spread of $V_{\text {pre }}$ through gap junctions. The ratio of transmission $\left(V_{\text {post }} / V_{\text {pre }}\right)$ was calcu- 
A

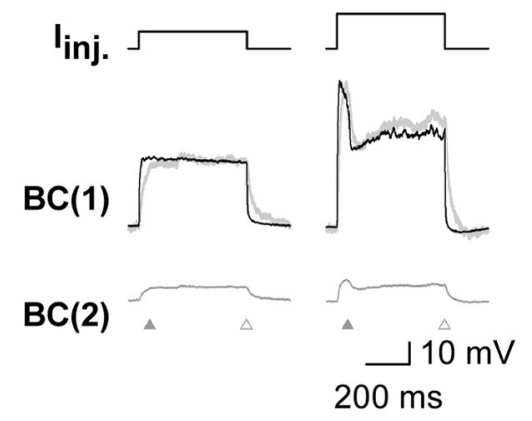

B

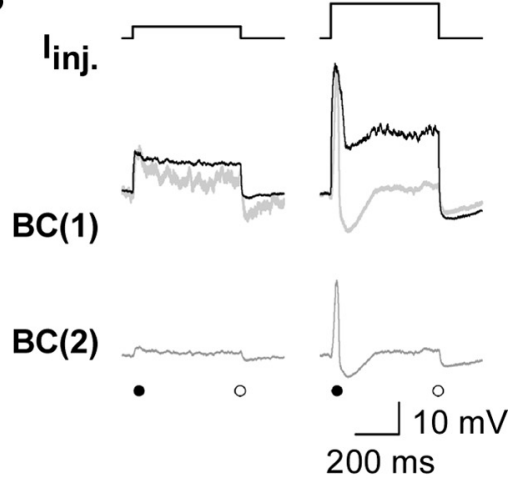

C

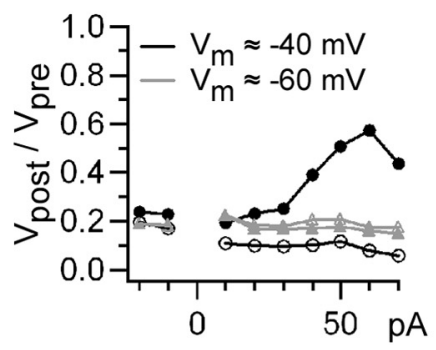

E
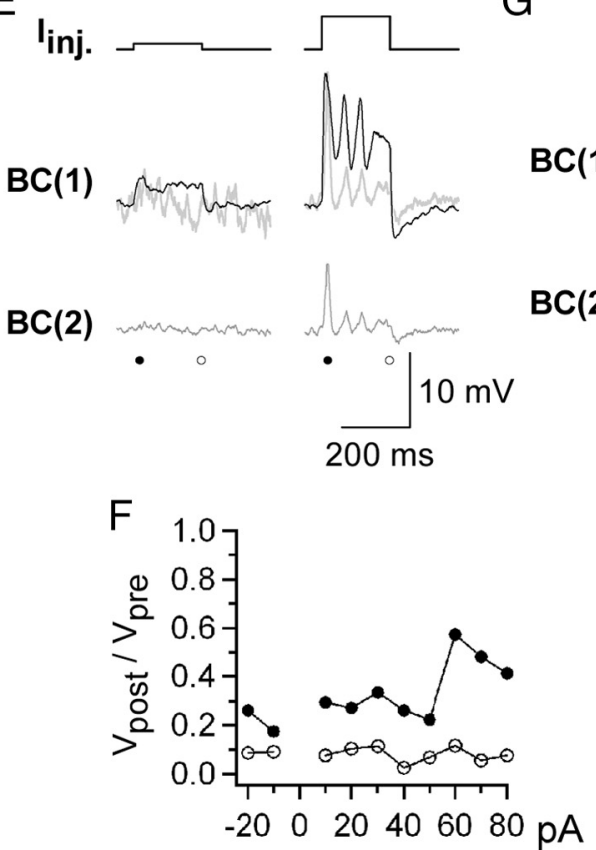

$\mathrm{D}$
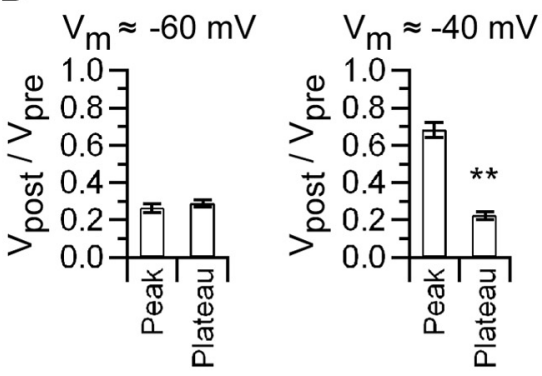

G

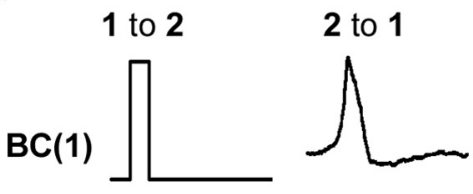

$\mathrm{BC}(2)$

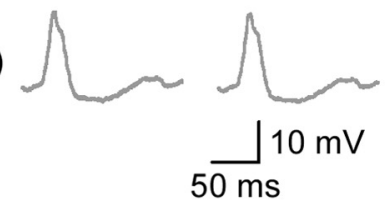

$\mathrm{H}$

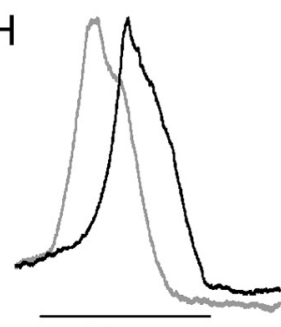

$50 \mathrm{~ms}$
Figure 4. Spread of $\mathrm{Ca}^{2+}$ spikes through gap junctions. Recordings were performed from a pair of $\mathrm{Mb} 1-\mathrm{BC}$ in the darkadapted retina. $A$, Passive spread. The membrane potential $\left(V_{m}\right)$ of both $B C(1)$ and $B C(2)$ was held around $-60 \mathrm{mV}$ by injection of a steady hyperpolarizing current. Then, the current pulse (top; left $50 \mathrm{pA}$, right $100 \mathrm{pA}$ ) was injected into the $B C(1)$, and the membrane potential was recorded from the $B C(1)$ (middle, black) and the $B C(2)$ (bottom, gray). The normalized $B C(2)$ response (middle, gray) is superimposed on the $\mathrm{BC}(1)$ response (middle, black). The control external solution and the $\mathrm{K}^{+}$-based pipette solution were used. $\boldsymbol{B}$, Active spread. Recordings were made from the same pair as in $A$, but $V_{\mathrm{m}}$ was held around $-40 \mathrm{mV}$. The current pulse intensity was 20 (left) and 60 (right) pA. C, Ratio of transmission. The amplitude ratio of the $B C(2)$ response $\left(V_{\text {post }}\right)$ to the $B C(1)$ response $\left(V_{\text {pre }}\right)$ was calculated at the peak and the plateau, and was plotted against the current pulse intensity. $V_{\mathrm{m}} \approx$ $-60 \mathrm{mV}$ (gray): peak, filled triangle; plateau, open triangle. $V_{\mathrm{m}} \approx-40 \mathrm{mV}$ (black): peak, filled circle; plateau, open circle. $\boldsymbol{D}$ Pooled data of the ratio of transmission. ${ }^{* *} p<0.01$, paired $t$ test, $n=9$ pairs $\left(V_{\mathrm{m}} \approx-60 \mathrm{mV}\right)$ and 21 pairs $\left(V_{\mathrm{m}} \approx-40 \mathrm{mV}\right)$. $\boldsymbol{E}_{\text {, }}$ Long-distance spread of $\mathrm{Ca}^{2+}$ spikes. Current injection experiment (same protocol as in $\boldsymbol{B}$ ) was performed from a pair of Mb1-BCs, between which one Mb1-BC intervened. Top, Injected current pulses (left, $10 \mathrm{pA}$; right, $60 \mathrm{pA}$ ). Middle, The $\mathrm{BC}(1)$ responses (black) and the normalized $\mathrm{BC}(2)$ responses (gray). Bottom, The $B C(2)$ responses. $\boldsymbol{F}$, Ratio of transmission. The amplitude ratio $\left(V_{\text {post }} / V_{\text {pre }}\right)$ was calculated from the data exemplified in $\boldsymbol{E}$ and plotted against the current pulse intensity. Peak, Solid circle; plateau, open circle. $\mathbf{G}$, Transmission ratio. Left, The brief depolarizing pulse (from -40 to $-10 \mathrm{mV}$ for $20 \mathrm{~ms}$ ) applied to the voltage-clamped $\mathrm{BC}(1)$ lated both at the peak and at the plateau, and each value was plotted against the intensity of $I_{\text {inj }}$ (Fig. 4C). Under hyperpolarized conditions $\left(V_{\mathrm{m}} \approx-60 \mathrm{mV}\right)$, the ratio of transmission remained nearly the same for both the peak and plateau (Fig. 4C, gray symbols). At the current intensity where the peak value was maximal, the ratio of transmission was $0.27 \pm 0.02$, which was not significantly different from the value at the plateau $(0.29 \pm 0.02, n=9$ pairs, $p=0.22$, paired $t$ test) (Fig. $4 D, V_{\mathrm{m}}$ $\approx-60 \mathrm{mV}$ ). On the other hand, under physiological conditions $\left(V_{\mathrm{m}} \approx-40\right.$ $\mathrm{mV}$ ), when a $\mathrm{Ca}^{2+}$ spike was evoked in the presynaptic cell, the ratio of transmission for the peak increased obviously but that for the plateau decreased slightly (Fig. 4C, peak, filled black circles; plateau, open black circles). The maximal ratio of transmission at the peak was $0.68 \pm 0.04$, which was significantly larger than that at the plateau $(0.22 \pm 0.02, n=21$ pairs, $p<$ 0.01 , paired $t$ test) (Fig. $4 D, V_{\mathrm{m}} \approx-40$ $\mathrm{mV}$ ). These results suggest that the transient response evoked in the postsynaptic cell may not be an electrotonic depolarization transmitted passively from the presynaptic cell but may be the $\mathrm{Ca}^{2+}$ spike newly generated in the postsynaptic cell.

To confirm the spread of $\mathrm{Ca}^{2+}$ spikes through the electrically coupled Mb1$\mathrm{BC}$ network, we recorded from a pair of Mb1-BCs, between which one Mb1-BC intervened. Both $\mathrm{BC}(1)$ and $\mathrm{BC}(2)$ were current-clamped at approximately -40 $\mathrm{mV}$. Injection of a subthreshold depolarizing current pulse into the $\mathrm{BC}(1)$ generated a small depolarization in the $\mathrm{BC}(2)$ (Fig. 4E, left). When $\mathrm{Ca}^{2+}$ spikes were induced in the $\mathrm{BC}(1)$ by large current injection, $\mathrm{Ca}^{2+}$ spikes were triggered in the $\mathrm{BC}(2)$ (Fig. $4 E$, right). The ratio of transmission at the peak was increased to $\sim 0.6$ (Fig. 4F), comparable to that obtained from neighboring $\mathrm{Mb} 1-\mathrm{BC}$ pairs (Fig. $4 \mathrm{D}$, $V_{\mathrm{m}} \approx-40 \mathrm{mV}$ ). On the other hand, the ratio of transmission at the plateau was $\sim 0.1$, much smaller than that obtained from neighboring Mb1-BC pairs (Fig. $4 D$, $V_{\mathrm{m}} \approx-40 \mathrm{mV}$ ). Similar results were obtained from other two pairs. These results suggest that $\mathrm{Ca}^{2+}$ spikes may travel a long distance with the aid of active firing

evoked a $\mathrm{Ca}^{2+}$ spike in the current-clamped $\mathrm{BC}(2) \cdot V_{\mathrm{m}}$ of the $B C(2)$ was approximately $-40 \mathrm{mV}$. Right, Application of the template of the recorded $\mathrm{Ca}^{2+}$ spike (gray) to the voltageclamped $\mathrm{BC}(2)$ resulted in generation of a $\mathrm{Ca}^{2+}$ spike (black) in the current-clamped $B C(1)$. The control external solution and the $\mathrm{K}^{+}$-based pipette solution were used. $\boldsymbol{H}$, Superimposed $\mathrm{Ca}^{2+}$ spikes shown in $\boldsymbol{G}$ right after normalization. 
whereas plateau potentials may decay passively in a short distance.

Under physiological conditions, the ratio of transmission at the peak was $0.68 \pm 0.04$, significantly smaller than 1.0 (Fig. $\left.4 D, V_{\mathrm{m}} \approx-40 \mathrm{mV}\right)(n=21$ pairs, $p<0.01$, paired $t$ test). The $\mathrm{Ca}^{2+}$ spike was evoked during depolarizing current injection (Fig. $4 B$ ), and thus, it was likely that the peak amplitude of the presynaptic response would be overestimated by the input resistance of the $\mathrm{BC}(1)$. This possibility was examined by using the following experimental protocol (Fig. 4G). A short depolarizing command pulse was applied to the $\mathrm{BC}(1)$ under voltage clamp (Fig. $4 G$, upper left, $\left.V_{\mathrm{h}}=-40 \mathrm{mV}\right)$ to evoke a $\mathrm{Ca}^{2+}$ spike in the $\mathrm{BC}(2)$ under current clamp (Fig. 4G, lower left). Then, the evoked $\mathrm{Ca}^{2+}$ spike was used as a template of the command voltage to the $\mathrm{BC}(2)$ under voltage clamp (Fig. 4G, lower right) to trigger a $\mathrm{Ca}^{2+}$ spike in the $\mathrm{BC}(1)$ under current clamp (Fig. 4G, upper right). The ratio of transmission at the peak was $0.96 \pm 0.05$, not significantly different from $1.0(n=6$ pairs, $p=0.48$, paired $t$ test). This experiment suggests that the $\mathrm{Ca}^{2+}$ spike generated in an Mb1-BC can trigger the $\mathrm{Ca}^{2+}$ spike with similar amplitude in neighboring Mb1-BCs.

When the $\mathrm{Ca}^{2+}$ spike was evoked in the presynaptic cell, there was a time lag of $\mathrm{Ca}^{2+}$ spike generation in the postsynaptic cell (Fig. $4 H$ ). The time lag was $9.1 \pm 0.96 \mathrm{~ms}$ ( $n=6$ pairs). This value was comparable to that obtained from the experiment as shown in Figure $4 B$ $(8.5 \pm 1.5 \mathrm{~ms}, n=21, p=0.85$, unpaired $t$ test), but almost half of that obtained from the remote Mb1-BC pairs (Fig. $4 E)(15.2 \pm 2.0 \mathrm{~ms}, n=3)$. These results suggest that $\mathrm{Ca}^{2+}$ spikes can spread the electrically coupled Mb1-BC network with a time lag.

\section{Effects of light and dark adaptation}

It is well known that retinal gap junctions are modulated by light and dark adaptation (Dong and McReynolds, 1991; Xin and Bloomfield, 1999). Thus, we investigated the effects of light and dark adaptation on the properties of the electrically coupled Mb1-BC network. First, we examined the tracer coupling between Mb1-BCs by injecting Neurobiotin into the axon terminal of an Mb1-BC in the whole-mount preparation (Fig. 5A). To evaluate the effects of light and dark adaptation on the tracer coupling, we calculated the ratio of the mean fluorescent intensity in the cell body of the surrounding tracer-coupled cells to the fluorescent intensity in the cell body of the injected cell. The ratio under light-adapted (LA) conditions was significantly higher than that under dark-adapted (DA) conditions (Fig. 5B) (LA: $0.052 \pm 0.004, n=39$; DA: $0.040 \pm 0.003, n=37, p<0.05$, unpaired $t$ test). This result indicates that the tracer coupling under LA conditions is stronger than that under DA conditions.
DA

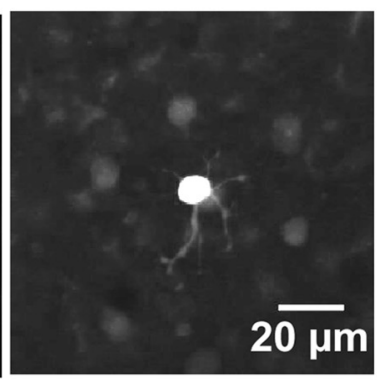

$\mathrm{B}$

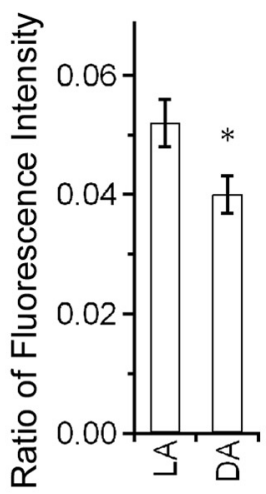

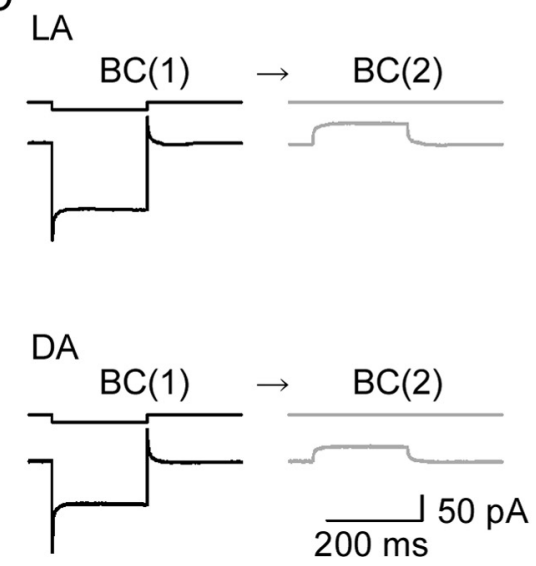

D
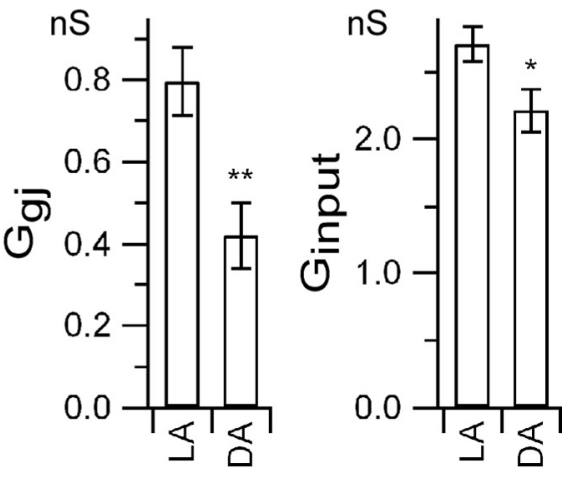

Figure 5. Effects of light adaptation. $\boldsymbol{A}, \boldsymbol{B}$, Tracer coupling. $\boldsymbol{A}$, Fluorescence images of tracer coupling among Mb1-BCs. Neurobiotin was introduced through a recording pipette into the axon terminal of a single Mb1-BC in the LA (left) or DA (right) wholeount preparation. Focus was at the level of inner nuclear layer. $\boldsymbol{B}$, Ratio of the fluorescence intensity, defined by the equation $\left.F_{s}-F_{\text {back }}\right) /\left(F_{c}-F_{\text {back }}\right)$, where $F_{s^{\prime}} F_{c^{\prime}}$ and $F_{\text {back }}$ are the averaged intensity of the surrounding somata, the intensity of the and 11 injected somata). DA, $n=8$ (data from 37 surrounding somata and 8 injected somata). $p<0.05$, unpaired $t$ test. $C, D$ Electrical coupling under LA and DA conditions. C, Hyperpolarizing voltage pulse from -60 to $-100 \mathrm{mV}$ was applied to the $B C(1)$ and the current responses were recorded from the $B C(1)$ and the $B C(2)$ in the slice preparation. $D$, Left, Pooled data of $G_{\text {gj: }}$. $L A$, $0.80 \pm 0.084 \mathrm{nS}(n=16)$. DA, $0.42 \pm 0.081 \mathrm{nS}(n=9) .{ }^{* *} p<0.01$, unpaired $t$ test. Right, Pooled data of $G_{\text {input }} G_{\text {input }}$ was obtained from the current response of the $\mathrm{BC}(1)$ to hyperpolarizing voltage pulse from -60 to $-100 \mathrm{mV}$. LA, $2.7 \pm 0.13 \mathrm{nS}(n=$ 18). DA, $2.2 \pm 0.16 \mathrm{nS}(n=32) .{ }^{*} p<0.05$, unpaired $t$ test.

Second, we examined the $G_{\mathrm{gj}}$ and the input conductance $\left(G_{\text {input }}\right)$ by performing paired recordings from neighboring Mb1-BCs in the slice preparation (Fig. $5 C$ ). The $G_{\mathrm{gj}}$, which was defined as the current response in the $\mathrm{BC}(2)$ divided by the voltage difference between the $\mathrm{BC}(1)$ and the $\mathrm{BC}(2)$, was significantly larger under LA conditions than under DA conditions (Fig. 5D, left) (LA: $0.80 \pm 0.08 \mathrm{nS}, n=16$, DA: $0.42 \pm 0.08 \mathrm{nS}, n=9, p<0.01$, unpaired $t$ test). The $G_{\text {input }}$, which was defined as the current response of the $\mathrm{BC}(1)$ divided by the amplitude of the voltage pulse applied to the $\mathrm{BC}(1)$, was significantly larger under LA conditions than under DA conditions (Fig. 5D, right) (LA: $2.71 \pm$ $0.13 \mathrm{nS}, n=32$, DA: $2.21 \pm 0.16 \mathrm{nS}, n=18, p<0.05$, unpaired $t$ test). Similar results were obtained in the whole-mount preparation for the $G_{\mathrm{gj}}$ (LA: $1.69 \pm 0.16 \mathrm{nS}, n=9$, DA: $1.09 \pm 0.07$ $\mathrm{nS}, n=6, p<0.05$, unpaired $t$ test, data not shown) and for the $G_{\text {input }}(\mathrm{LA}: 6.43 \pm 0.40 \mathrm{nS}, n=18, \mathrm{DA}: 4.78 \pm 0.16 \mathrm{nS}, n=$ $12, p<0.01$, unpaired $t$ test, data not shown). These results suggest that light and dark adaptation may affect the signal transmission between gap junctions because the properties of the electrically coupled Mb1-BC network were modified by light and dark adaptation. 


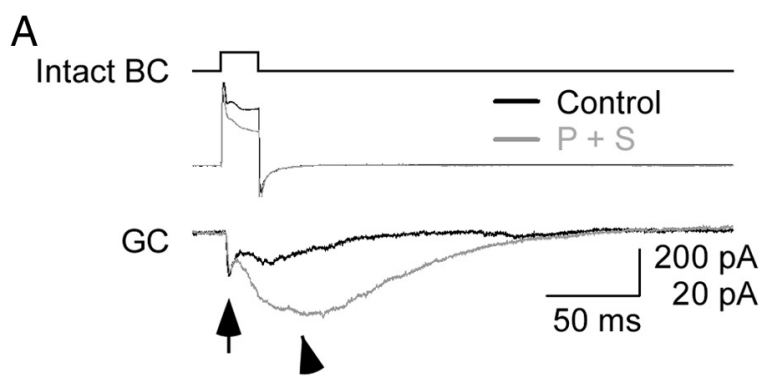

B
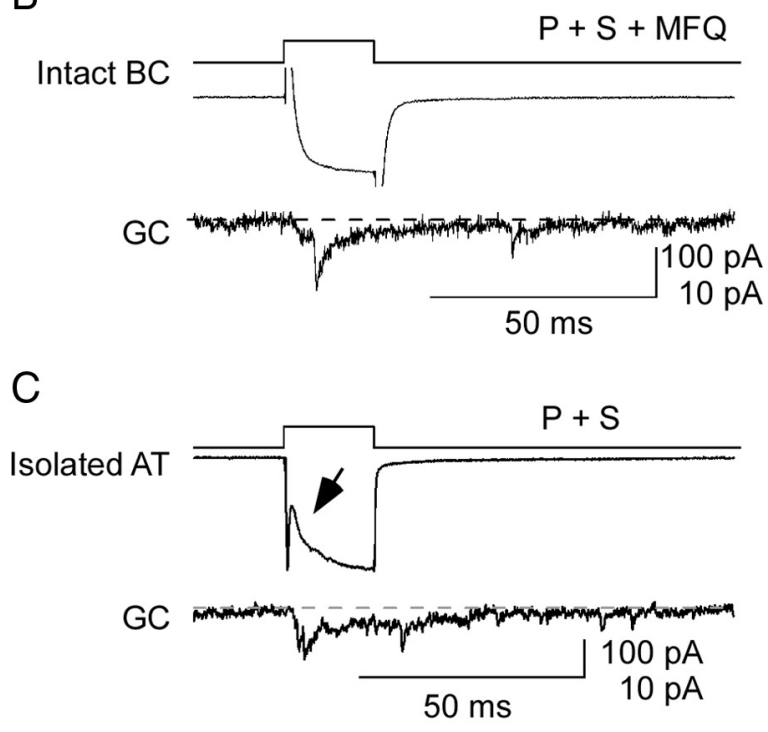

D

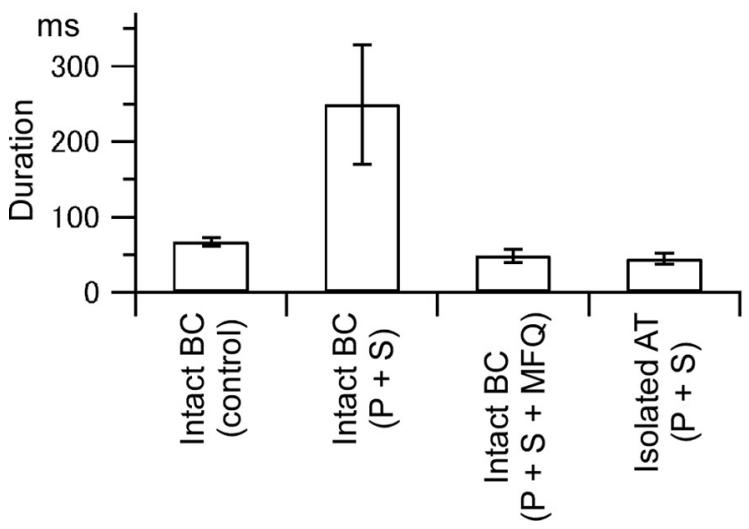

Figure 6. Synaptic transmission from Mb1-BC to GC. A, Long-lasting EPSC evoked by a brief depolarization of $\mathrm{Mb} 1-\mathrm{BC}$. Paired recordings from an intact Mb1-BC (intact $\mathrm{BC}$ ) and a postsynaptic ganglion cell (GC) in the dark-adapted retina. A depolarizing pulse (from -60 to $-10 \mathrm{mV}$ for $20 \mathrm{~ms}$ ) (top) applied to the intact BC evoked an outward current (middle) in the intact BC and an EPSC (bottom) in the $\mathrm{GC}$ voltage clamped at $-60 \mathrm{mV}$. Recordings were performed in the control solution (Control, black traces), and then in the presence of picrotoxin (200 $\mu \mathrm{M})$ and strychnine $(10 \mu \mathrm{M})(\mathrm{P}+\mathrm{S}$, gray traces). The pipette for the intact $\mathrm{BC}$ was filled with the $\mathrm{Cs}^{+}$-based pipette solution and that for $\mathrm{GC}$ with the $\mathrm{Cs}^{+}$-based pipette solution containing QX-314 (5 mM). The evoked EPSC consisted of the fast (arrow) and slow (arrowhead) components. $\boldsymbol{B}$, Effects of a gap junction blocker on the synaptic transmission from Mb1-BC to GC. Recordings were made from a pair of an intact $\mathrm{BC}$ and a postsynaptic $\mathrm{GC}$ in the dark-adapted retinal slice preparation, which was preincubated for $>30$ min with MFQ $(10 \mu \mathrm{M})$, picrotoxin $(200 \mu \mathrm{m})$, strychnine $(10 \mu \mathrm{m})$, and L-AP4 $(100 \mu \mathrm{M})$. The pipette for the intact BC was filled with the $\mathrm{Cs}^{+}$-based pipette solution and that for the $\mathrm{GC}$ with the $\mathrm{Cs}^{+}$-based pipette solution containing QX-314 (5 mM). A brief depolarization (top; from -60 to $-10 \mathrm{mV}$ for $50 \mathrm{~ms}$ ) of the intact $\mathrm{BC}$ evoked a $\mathrm{Ca}^{2+}$ current (middle) in the intact $\mathrm{BC}$ and a transient EPSC (bottom) in the GC. The dotted line indicates the basal current at the holding potential of $-60 \mathrm{mV}$. $C$, Recordings from a pair of an isolated axon terminal (isolated AT) of Mb1-BC and a
Paired current-clamp recordings were performed from neighboring Mb1-BCs in the light-adapted retinal slice preparation $\left(V_{\mathrm{m}} \approx\right.$ $-40 \mathrm{mV})$. In $\sim 70 \%$ of the BC(1)s $(n=25)$, injection of depolarizing pulses failed to evoke $\mathrm{Ca}^{2+}$ spikes (supplemental Fig. $2 \mathrm{~A}$, available at www.jneurosci.org as supplemental material). The ratio of transmission $\left(V_{\text {post }} / V_{\text {pre }}\right)$ remained nearly the same for both the peak and plateau when the current intensity was changed (supplemental Fig. $2 B$, available at www.jneurosci.org as supplemental material), but the $V_{\text {post }} / V_{\text {pre }}$ in the peak was significantly larger than that in the plateau (supplemental Fig. 2C, available at www.jneurosci.org as supplemental material), suggesting that voltage- and $\mathrm{Ca}^{2+}$ dependent conductances in the postsynaptic $\mathrm{BC}(2)$ would be activated. In $\sim 30 \%$ of the $\mathrm{BC}(1) \mathrm{s}$, however, depolarizing current evoked $\mathrm{Ca}^{2+}$ spikes, which in turn could trigger $\mathrm{Ca}^{2+}$ spikes in the postsynaptic $\mathrm{BC}(2)$ (supplemental Fig. $2 D, E$, available at www. jneurosci.org as supplemental material $(n=6)$. Comparison of the $\mathrm{Ca}^{2+}$ spike waveform in the postsynaptic $\mathrm{BC}(2)$ under LA conditions with that under DA conditions (supplemental Fig. $2 F$, available at www.jneurosci.org as supplemental material) revealed that the half-width of the $\mathrm{Ca}^{2+}$ spike under LA conditions was significantly longer than that under DA conditions (supplemental Fig. $2 G$, available at www.jneurosci.org as supplemental material) (LA: $37.3 \pm 8.1$ ms, $n=6$, DA: $21.6 \pm 1.6 \mathrm{~ms}, n=21, p<0.01$, unpaired $t$ test). The time lag between Mb1-BC pairs for generating $\mathrm{Ca}^{2+}$ spikes under LA conditions was $19.7 \pm 2.9 \mathrm{~ms}(n=6)$, which was significantly longer than that under DA conditions $(8.5 \pm 1.5 \mathrm{~ms}, n=21, p<$ 0.01 , unpaired $t$ test). These results indicate that the signal transmission with the $\mathrm{Ca}^{2+}$ spikes in the electrically coupled Mb1-BC network is regulated by light and dark adaptation.

\section{Long-lasting EPSC evoked by a brief depolarization of an $\mathrm{Mb1-BC}$}

The electrically coupled Mb1-BC network may affect the chemical synaptic transmission from Mb1-BCs to postsynaptic GCs. By applying dual whole-cell voltage-clamp techniques to the slice preparation, we examined the kinetics of synaptic transmission from $\mathrm{Mb} 1-\mathrm{BC}$ to $\mathrm{GC}$. Unexpected responses were generated when a brief depolarizing pulse was applied to an intact Mb1-BC (Fig. 6A, top). First, the depolarizing pulse evoked frequently an outward current in the Mb1-BC, regardless of blockade of $\mathrm{K}^{+}$ currents by intracellular $\mathrm{Cs}^{+}$introduced through a recording pipette (Fig. 6A, middle black trace). Under similar recording conditions where the voltage- and $\mathrm{Ca}^{2+}$-dependent $\mathrm{K}^{+}$currents were blocked intracellularly, the inward L-type $\mathrm{Ca}^{2+}$ current $\left(I_{\mathrm{Ca}}\right)$ could be observed in Mb1-BCs isolated from the goldfish retina (Tachibana and Okada, 1991; Palmer et al., 2003b). Second, the depolarizing pulse evoked a long-lasting EPSC in the postsynaptic GC voltage clamped at $-60 \mathrm{mV}$, where NMDA receptors would be mostly blocked by $\mathrm{Mg}^{2+}$ (Fig. 6A, bottom black

$\leftarrow$

postsynaptic GC in the dark-adapted retina. Both were voltage clamped at $-60 \mathrm{mV}$. A brief depolarization (top; to $-10 \mathrm{mV}$ for $20 \mathrm{~ms}$ ) of the isolated AT evoked a $\mathrm{Ca}^{2+}$ current (middle) in the isolated AT and an EPSC (bottom) in the GC. The arrow indicates the proton feedback. The dotted line indicates the basal current at the holding potential of $-60 \mathrm{mV}$. The external solution contained picrotoxin $(200 \mu \mathrm{M})$, strychnine $(10 \mu \mathrm{M})$, and TTX $(0.5 \mu \mathrm{M})$, and the $\mathrm{Cs}^{+}$-based pipette solution. $\boldsymbol{D}$, Pooled data of duration of the EPSCs evoked in the postsynaptic GCs. Duration was defined as the response width of $10 \%$ of the peak amplitude. Data were obtained from five pairs of an intact $B C$ and $a G C$ in control condition [Intact $B C$ (control)], five pairs of an intact $B C$ and $a G C$ in the solution containing picrotoxin and strychnine [Intact $B C(P+S)$ ], five pairs of an intact $B C$ and $a \mathrm{GC}$ in the solution containing picrotoxin, strychnine, and mefloquine [Intact $B C(P+S+M F Q)]$, and three pairs of an isolated $A T$ and a GC in the solution containing picrotoxin and strychnine [lsolated $A T(P+S)]$. 
trace) (duration defined as the response width of $10 \%$ of the peak amplitude: $67.3 \pm 5.8 \mathrm{~ms}, n=5$ [Fig. $6 \mathrm{D}$, Intact BC (control)]). The evoked EPSC seemed to consist of the fast and slow components. The fast component appeared soon after the onset of Mb1-BC depolarization (Fig. 6A, arrow), and then the prominent slow component developed during depolarization and decayed gradually after repolarization (Fig. 6A, arrowhead).

It was likely that the evoked EPSC shown in Figure $6 A$ was modulated by inhibitory amacrine cells, i.e., inhibitory feedback to the Mb1-BC and/or inhibitory feedforward to the postsynaptic GC (Lukasiewicz and Werblin, 1990; Han et al., 1997; Matsui et al., 2001; Vigh and von Gersdorff, 2005). Blockade of inhibitory synaptic transmission by GABA- and glycine-receptor blockers (picrotoxin and strychnine, respectively) reduced the outward current in the Mb1-BC (Fig. 6A, middle gray trace), suggesting that the inhibitory feedback to the Mb1-BC was suppressed by the pharmacological treatment. On the other hand, this treatment enhanced the evoked EPSC in the postsynaptic GC [Fig. 6A, bottom gray trace $(\mathrm{P}+\mathrm{S})$ ] (duration: $249.5 \pm 79.5 \mathrm{~ms}, n=5$ [Fig. $6 D$, Intact $\mathrm{BC}(\mathrm{P}+\mathrm{S})]$ ). Specifically, the slow component of the EPSC became larger in amplitude and longer in duration than control.

To evaluate the effect of the electrical coupling between Mb1-BCs on the long-lasting EPSC, we performed two sets of experiments. First, the slice preparation was preincubated with a gap junction blocker MFQ and then paired recordings were made from an $\mathrm{Mb} 1-\mathrm{BC}$ and a GC (Fig. 6B). A brief depolarizing pulse applied to the $\mathrm{Mb} 1-\mathrm{BC}$ induced an inward $\mathrm{Ca}^{2+}$ current in the Mb1-BC (Fig. $6 B$, middle trace) and evoked a transient EPSC in the postsynaptic GC with a short delay (Fig. $6 B$, bottom trace) (duration: $48.6 \pm 8.9$ ms, $n=5$ [Fig. $6 D$, Intact BC (P $+\mathrm{S}+\mathrm{MFQ})$ ]. The long-lasting EPSC such as shown in Figure $6 A$ was not observed.

Second, we made paired recordings from an isolated axon terminal (AT) of the Mb1-BC and a postsynaptic GC. As we already showed, the isolated axon terminal of Mb1-BC was not electrically coupled with neighboring Mb1-BCs (Fig. 1E,F). A brief depolarizing pulse applied to the isolated AT induced an inward $\mathrm{Ca}^{2+}$ current in the AT and evoked a transient EPSC in the postsynaptic GC (Fig. $6 C$, middle and bottom traces, respectively) (duration: $44.0 \pm 7.3$ $\mathrm{ms}, n=3$ [Fig. $6 D$, Isolated AT $(\mathrm{P}+\mathrm{S})$ ]. A transient reduction of the $\mathrm{Ca}^{2+}$ current (Fig. $6 \mathrm{C}$, arrow) could be ascribed to the proton feedback (Palmer et al., 2003a) because inhibitory synaptic transmission had been blocked by picrotoxin and strychnine (in Fig. $6 B$, the proton feedback was obscured by a large capacitive transient at the onset of depolarization, probably because of the large membrane capacitance arising from the voltage-clamped Mb1-BC with the cell body and dendrites, and perhaps from neighboring Mb1-BCs partially connected through gap junctions even in the presence of MFQ). These results suggest that the slow component of the long-lasting EPSC evoked in the postsynaptic GC (Fig. 6A) may be ascribed to the multiple inputs from the electrically coupled presynaptic Mb1-BCs.

\section{Discussion}

The electrophysiological and immunohistochemical results indicate that gap junctions are located at the distal dendrites of Mb1-BCs (Fig. $1 E-H$; supplemental Fig. 1, available at www.jneurosci.org as supplemental material). In our previous paper (Midorikawa et al., 2007), we reconstructed the whole terminal of an Mb1-BC from serial ultrathin sections, but we did not find the gap junction-like structure in the terminal telodendria. Since goldfish Ma (OFF type) BCs are coupled via gap junctions located at their axon terminals and telodendria in the IPL (Marc et al., 1988), the subcellular location of gap junctions may be different from subtype to subtype.
In paired-cell recording experiments the $G_{\mathrm{gj}}$ is conventionally defined as the amplitude of the transjunctional current divided by the transjunctional voltage difference. The calculated $G_{\mathrm{gj}}$ is valid only if electrical coupling is limited to the recorded cell pair. However, each Mb1-BC is electrically coupled to surrounding Mb1-BCs (Fig. $1 A)$. To estimate the "real" $G_{\mathrm{gj}}$ between a pair of Mb1-BCs, we constructed a hexagonal Mb1-BC network model by connecting the passive equivalent-circuit model of Mb1-BC (Mennerick et al., 1997 ) with the gap junction conductance (i.e., the "real" $G_{\mathrm{gj}}$ ) (supplemental Fig. $3 A, B$, available at www.jneurosci.org as supplemental material). Using the $G_{\mathrm{gj}}$ and $G_{\text {input }}$ obtained from the experiments in the whole-mount preparation under LA and DA conditions, we performed model simulation with NEURON (Hines and Carnevale, 1997). A stimulating pulse was applied to the axon terminal of the model cell (supplemental Fig. 3A, arrow, available at www.jneurosci. org as supplemental material), and the responses were measured from the axon terminals of the stimulated cell, $\# 0$, and the directly connected cell, \#1 (supplemental Fig. 3B, available at www.jneurosci. org as supplemental material). The "real" $G_{\mathrm{gj}}$ was estimated to be in the range of 2-3 nS under LA conditions and 1-2 nS under DA conditions (supplemental Fig. 3C, available at www.jneurosci.org as supplemental material). The number of fully opened gap junction channels under LA conditions may be in the range of 133-200, assuming that the single channel conductance of $\mathrm{Cx} 36$ is $\sim 15 \mathrm{pS}$ (Teubner et al., 2000). If gap junctions $[\sim 10 \mathrm{~nm}$ in diameter (Raviola and Gilula, 1975)] are closely aggregated, the area of contact between Mb1-BCs would be a square at least $0.12-0.14 \mu \mathrm{m}$ on a side. Taking into account the low open probability and wide spacing of gap junctions, our estimated value seems to be comparable to that reported by the EM study of the gap junctions between distal dendrites of OFF-type BCs in the black bass retina [the length of closed membrane apposition; 0.3-0.4 $\mu \mathrm{m}$ (Umino et al., 1994)].

The isolated Mb1-BCs are almost equipotential (Heidelberger and Matthews, 1992; Tachibana et al., 1993). However, Mb1-BCs in the retina are electrically coupled through gap junctions at the distal dendrites, and thus the potential change at the axon terminal of an $\mathrm{Mb1-BC}$ would be distorted at its dendrites and at the axon terminals of neighboring Mb1-BCs by the cable properties. Model simulation using the network model (supplemental Fig. 3D, available at www.jneurosci.org as supplemental material) shows that the potential change at the axon terminal of cell $\# 0$ may be reduced to $68.6 \%$ at the distal dendrite of cell $\# 0$ and to $21.6 \%$ at the axon terminal of cell \#1 (the $G_{\text {gj-real }}$ was set to $2 \mathrm{nS}$ ). The latter value corresponds well to the observed coupling ratio $\left(V_{\text {post }} / V_{\text {pre }}\right)$ in the whole-mount preparation (data not shown, but see Figs. 5 and 6 obtained from the slice preparation).

It has been assumed that signal averaging and noise reduction through gap junctions may be important for early visual information processing (DeVries et al., 2002; Veruki and Hartveit, 2002a). However, the transfer of signals by a passive, electrotonic mechanism may not be a main function of the Mb1-BC network because the spread of potential changes may be limited (supplemental Fig. $3 E$, available at www.jneurosci.org as supplemental material), and because the membrane potential fluctuations recorded from neighboring Mb1-BCs were not well synchronized; a half-width of the peak at $0 \mathrm{~ms}$ time shift in the cross-correlogram was $\sim 50 \mathrm{~ms}$ (data not shown), much broader than that of spiking neurons $(\sim 7 \mathrm{~ms})$ (Brivanlou et al., 1998; Veruki and Hartveit, 2002a; Ackert et al., 2006).

Active membrane conductances help to communicate between Mb1-BCs. $\mathrm{Ca}^{2+}$ spikes could successfully spread the electrically coupled Mb1-BC network (Fig. 4). Although mammalian AII amacrine cells are electrically coupled each other through gap junctions 
(Cx36) (Feigenspan et al., 2001; Mills et al., 2001) and their coupling ratio $[\sim 0.3$ (Veruki and Hartveit, 2002a)] is comparable to that of Mb1-BCs $(\sim 0.3)$ (Fig. $4 D$, Plateau), the $\mathrm{Na}^{+}$spike generated in an AII amacrine cell failed to trigger the $\mathrm{Na}^{+}$spike in its neighboring AII amacrine cells (Veruki and Hartveit, 2002a). Such discrepancy may be explained by the following reasons. First, $\mathrm{Ca}^{2+}$ spikes in $\mathrm{Mb} 1-\mathrm{BCs}$ are much longer in duration than $\mathrm{Na}^{+}$spikes in AII amacrine cells, and thus $\mathrm{Ca}^{2+}$ spikes may evoke relatively large depolarization in its neighboring Mb1-BCs through gap junctions with the low-pass filtering property. Second, the resting membrane potential of Mb1-BCs is approximately $-40 \mathrm{mV}$ (see Materials and Methods), near the activation threshold of the L-type $\mathrm{Ca}^{2+}$ current, whereas the resting membrane potential of AII amacrine cells is approximately $-70 \mathrm{mV}$ and the activation threshold of the $\mathrm{Na}^{+}$current is approximately $-55 \mathrm{mV}$ (Tamalu and Watanabe, 2007). Thus, the $\mathrm{Ca}^{2+}$ spike generated in the axon terminal of an Mb1-BC may depolarize the membrane potential of its neighboring Mb1-BCs large enough to trigger the $\mathrm{Ca}^{2+}$ spike. It has been reported that gap junctions can be modulated by intracellular $\mathrm{Ca}^{2+}$ (Burr et al., 2005; Alev et al., 2008). However, the $\mathrm{Ca}^{2+}$ channels are localized to the axon terminal of Mb1-BCs (Tachibana et al., 1993), and thus the gap junctions located at the distal dendrites may have a merit that they are not easily modulated by $\mathrm{Ca}^{2+}$ diffused from the axon terminal.

We found that the gap junction conductance between Mb1-BCs under LA conditions was larger than that under DA conditions (Fig. $5 D$ ). Our results seem to be against the notion that small $G_{\mathrm{gj}}$ in the light may improve the spatial resolution while large $G_{\mathrm{gj}}$ in the dark may improve the signal detection [horizontal cells: Dong and McReynolds (1991); amacrine cells: Xin and Bloomfield (1999)]. However, we have to take into account $G_{\mathrm{gj}}$ and $G_{\text {input }}$, both of which were increased by light adaptation (Fig. $5 D$ ). Model simulation was performed to evaluate the effects of $G_{\mathrm{gj}}$ and $G_{\text {input }}$ on the receptive field size of the Mb1-BC network (supplemental Fig. $3 B, E$, available at www.jneurosci.org as supplemental material). Depolarizing current was injected into the axon terminal of cell \#0, and the response amplitude was measured at the array of axon terminals (cell \#0 to cell $\# 7)$. As the $G_{\text {gj-real }}$ was systematically increased, the response amplitude at cell \#0 gradually decreased, but the response amplitude in coupled cells changed little (supplemental Fig. 3E, available at www. jneurosci.org as supplemental material). This model simulation suggests that the receptive field size of Mb1-BC may not be seriously changed even if the coupling conductance is modulated by light and dark adaptation.

The signal transmission with $\mathrm{Ca}^{2+}$ spikes in the Mb1-BC network was regulated by light and dark adaptation (supplemental Fig. 2, available at www.jneurosci.org as supplemental material). The threshold for $\mathrm{Ca}^{2+}$ spike generation should depend on the net current flow, i.e., the relative amount of the $\mathrm{Ca}^{2+}$ current influx, the voltage- and $\mathrm{Ca}^{2+}$-activated $\mathrm{K}^{+}$current efflux, the leak current through gap junctions, and others. It has been reported that the $\mathrm{Ca}^{2+}$ current and the $\mathrm{K}^{+}$current are regulated by dopamine, the extracellular concentration of which is modulated by light adaptation (Heidelberger and Matthews, 1994; Fan and Yazulla, 1999). Therefore, it is possible that the generation rate and waveform of the $\mathrm{Ca}^{2+}$ spike may depend on the light-adaptation level (Protti et al., 2000).

A brief depolarization of an Mb1-BC evoked a long-lasting EPSC in the postsynaptic GC (Fig. 6A). We showed that the long-lasting EPSC could be ascribed mainly to the spread of $\mathrm{Ca}^{2+}$ spikes in the electrically coupled Mb1-BC network (Fig. 6B, C). One may argue that the long-lasting EPSC might be ascribed to the copious asynchronous release of glutamate following $\mathrm{Ca}^{2+}$ current termination (Gleason et al., 1994; Goda and Stevens, 1994; Rieke and Schwartz,
1996). However, asynchronous release from the Mb1-BC was evident only after the termination of a long ( $\sim 200 \mathrm{~ms})$ depolarization (von Gersdorff et al., 1998), and thus, it seems unlikely that the brief depolarization $(20 \mathrm{~ms})$ could exhibit asynchronous release strong enough to evoke the long-lasting EPSC. Delayed activation of NMDA receptors in GCs (Matsui et al., 1998; Vigh and von Gersdorff, 2005) would also contribute to the longlasting EPSC. However, it seems unlikely because NMDA receptors could be mostly blocked by extracellular $\mathrm{Mg}^{2+}$ at the holding potential of $-60 \mathrm{mV}$ (Nowak et al., 1984), and that application of D-AP5 did not change the duration of the longlasting EPSC (data not shown). Therefore, the slow component of the long-lasting EPSC may be generated by the multiple inputs from the electrically coupled presynaptic Mb1-BCs.

\section{References}

Ackert JM, Wu SH, Lee JC, Abrams J, Hu EH, Perlman I, Bloomfield SA (2006) Light-induced changes in spike synchronization between coupled ON direction selective ganglion cells in the mammalian retina. J Neurosci 26:4206-4215.

Alev C, Urschel S, Sonntag S, Zoidl G, Fort AG, Höher T, Matsubara M, Willecke K, Spray DC, Dermietzel R (2008) The neuronal connexin36 interacts with and is phosphorylated by CaMKII in a way similar to CaMKII interaction with glutamate receptors. Proc Natl Acad Sci U S A 105:20964-20969.

Arai I, Yamada Y, Asaka T, Tachibana M (2004) Light-evoked oscillatory discharges in retinal ganglion cells are generated by rhythmic synaptic inputs. J Neurophysiol 92:715-725.

Bloomfield SA, Völgyi B (2009) The diverse functional roles and regulation of neuronal gap junctions in the retina. Nat Rev Neurosci 10:495-506.

Bloomfield SA, Xin D, Persky SE (1995) A comparison of receptive field and tracer coupling size of horizontal cells in the rabbit retina. Vis Neurosci 12:985-999.

Brivanlou IH, Warland DK, Meister M (1998) Mechanisms of concerted firing among retinal ganglion cells. Neuron 20:527-539.

Burr GS, Mitchell CK, Keflemariam YJ, Heidelberger R, O’Brien J (2005) Calcium-dependent binding of calmodulin to neuronal gap junction proteins. Biochem Biophys Res Commun 335:1191-1198.

Burrone J, Lagnado L (1997) Electrical resonance and $\mathrm{Ca}^{2+}$ influx in the synaptic terminal of depolarizing bipolar cells from the goldfish retina. J Physiol 505:571-584.

Cruikshank SJ, Hopperstad M, Younger M, Connors BW, Spray DC, Srinivas M (2004) Potent block of Cx36 and Cx50 gap junction channels by mefloquine. Proc Natl Acad Sci U S A 101:12364-12369.

DeVries SH, Qi X, Smith R, Makous W, Sterling P (2002) Electrical coupling between mammalian cones. Curr Biol 12:1900-1907.

Dong CJ, McReynolds JS (1991) The relationship between light, dopamine release and horizontal cell coupling in the mudpuppy retina. J Physiol 440:291-309.

Famiglietti EV Jr, Kaneko A, Tachibana M (1977) Neuronal architecture of on and off pathways to ganglion cells in carp retina. Science 198:12671269.

Fan SF, Yazulla S (1999) Modulation of voltage-dependent $\mathrm{K}^{+}$currents $\left(\mathrm{I}_{\mathrm{K}(\mathrm{V})}\right)$ in retinal bipolar cells by ascorbate is mediated by dopamine $\mathrm{D} 1$ receptors. Vis Neurosci 16:923-931.

Feigenspan A, Teubner B, Willecke K, Weiler R (2001) Expression of neuronal connexin 36 in AII amacrine cells of the mammalian retina. J Neurosci 21:230-239.

Gleason E, Borges S, Wilson M (1994) Control of transmitter release from retinal amacrine cells by $\mathrm{Ca}^{2+}$ influx and efflux. Neuron 13:1109-1117.

Goda Y, Stevens CF (1994) Two components of transmitter release at a central synapse. Proc Natl Acad Sci U S A 91:12942-12946.

Han Y, Zhang J, Slaughter MM (1997) Partition of transient and sustained inhibitory glycinergic input to retinal ganglion cells. J Neurosci 17:3392-3400.

Harris AL (2001) Emerging issues of connexin channels: biophysics fill of the gap. Q Rev Biophys 34:325-472.

Heidelberger R, Matthews G (1992) Calcium influx and calcium current in 
single synaptic terminals of goldfish retinal bipolar neurons. J Physiol 447:235-256.

Heidelberger R, Matthews G (1994) Dopamine enhances Ca2+ responses in synaptic terminals of retinal bipolar neurons. Neuroreport 5:729-732.

Hines ML, Carnevale NT (1997) The NEURON simulation environment. Neural Comput 9:1179-1209.

Hosoi N, Arai I, Tachibana M (2005) Group III metabotropic glutamate receptors and exocytosed protons inhibit L-type calcium currents in cones but not in rods. J Neurosci 25:4062-4072.

Hu C, Bi A, Pan ZH (2009) Differential expression of three T-type calcium channels in retinal bipolar cells in rats. Vis Neurosci 26:177-187.

Hull C, Li GL, von Gersdorff H (2006) GABA transporters regulate a standing $\mathrm{GABA}_{\mathrm{C}}$ receptor-mediated current at a retinal presynaptic terminal. J Neurosci 26:6979-6984.

Jacoby RA, Marshak DW (2000) Synaptic connections of DB3 diffuse bipolar cell axons in macaque retina. J Comp Neurol 416:19-29.

Kaneko A (1973) Receptive field organization of bipolar and amacrine cells in the goldfish retina. J Physiol 235:133-153.

Kaneko A, Tachibana M (1985) A voltage-clamp analysis of membrane currents in solitary bipolar cells dissociated from Carassius auratus. J Physiol 358:131-152.

Kolb H (1979) The inner plexiform layer in the retina of the cat: electron microscopic observations. J Neurocytol 8:295-329.

Kujiraoka T, Saito T (1986) Electrical coupling between bipolar cells in carp retina. Proc Natl Acad Sci U S A 83:4063-4066.

Lukasiewicz PD, Werblin FS (1990) The spatial distribution of excitatory and inhibitory inputs to ganglion cell dendrites in the tiger salamander retina. J Neurosci 10:210-221.

Ma YP, Pan ZH (2003) Spontaneous regenerative activity in mammalian retinal bipolar cells: roles of multiple subtypes of voltage-dependent $\mathrm{Ca}^{2+}$ channels. Vis Neurosci 20:131-139.

Ma YP, Cui J, Pan ZH (2005) Heterogeneous expression of voltagedependent $\mathrm{Na}^{+}$and $\mathrm{K}^{+}$channels in mammalian retinal bipolar cells. Vis Neurosci 22:119-133.

Marc RE, Liu WL, Muller JF (1988) Gap junctions in the inner plexiform layer of the goldfish retina. Vision Res 28:9-24.

Massey SC, O’Brien JJ, Trexler EB, Li W, Keung JW, Mills SL, O’Brien J (2003) Multiple neuronal connexins in the mammalian retina. Cell Commun Adhes 10:425-430.

Matsui K, Hosoi N, Tachibana M (1998) Excitatory synaptic transmission in the inner retina: paired recordings of bipolar cells and neurons of the ganglion cell layer. J Neurosci 18:4500-4510.

Matsui K, Hasegawa J, Tachibana M (2001) Modulation of excitatory synaptic transmission by $\mathrm{GABA}_{\mathrm{C}}$ receptor-mediated feedback in the mouse inner retina. J Neurophysiol 86:2285-2298.

McMahon DG, Mattson MP (1996) Horizontal cell electrical coupling in the giant danio: synaptic modulation by dopamine and synaptic maintenance by calcium. Brain Res 718:89-96.

Mennerick S, Zenisek D, Matthews G (1997) Static and dynamic membrane properties of large-terminal bipolar cells from goldfish retina: experimental test of a compartment model. J Neurophysiol 78:51-62.

Midorikawa M, Tsukamoto Y, Berglund K, Ishii M, Tachibana M (2007) Different roles of ribbon-associated and ribbon-free active zones in retinal bipolar cells. Nat Neurosci 10:1268-1276.

Mills SL, O'Brien JJ, Li W, O'Brien J, Massey SC (2001) Rod pathways in the mammalian retina use connexin 36. J Comp Neurol 436:336-350.

Münch TA, da Silveira RA, Siegert S, Viney TJ, Awatramani GB, Roska B (2009) Approach sensitivity in the retina processed by a multifunctional neural circuit. Nat Neurosci 12:1308-1316.

Negishi K, Kato S, Teranishi T (1988) Dopamine cells and rod bipolar cells contain protein kinase C-like immunoreactivity in some vertebrate retinas. Neurosci Lett 94:247-252.

Nelson R (1977) Cat cones have rod input: a comparison of the response properties of cones and horizontal cell bodies in the retina of the cat. J Comp Neurol 172:109-135.

Nowak L, Bregestovski P, Ascher P, Herbet A, Prochiantz A (1984) Magnesium gates glutamate-activated channels in mouse central neurones. Nature 307:462-465.

Okada T, Horiguchi H, Tachibana M (1995) $\mathrm{Ca}^{2+}$-dependent $\mathrm{Cl}^{-}$current at the presynaptic terminals of goldfish retinal bipolar cells. Neurosci Res 23:297-303
Palmer MJ (2006) Modulation of $\mathrm{Ca}^{2+}$-activated $\mathrm{K}^{+}$currents and $\mathrm{Ca}^{2+}$ dependent action potentials by exocytosis in goldfish bipolar cell terminals. J Physiol 572:747-762.

Palmer MJ, Hull C, Vigh J, von Gersdorff H (2003a) Synaptic cleft acidification and modulation of short-term depression by exocytosed protons in retinal bipolar cells. J Neurosci 23:11332-11341.

Palmer MJ, Taschenberger H, Hull C, Tremere L, von Gersdorff H (2003b) Synaptic activation of presynaptic glutamate transporter currents in nerve terminals. J Neurosci 23:4831-4841.

Protti DA, Flores-Herr N, von Gersdorff H (2000) Light evokes $\mathrm{Ca}^{2+}$ spikes in the axon terminal of a retinal bipolar cell. Neuron 25:215-227.

Raviola E, Gilula NB (1975) Intramembrane organization of specialized contacts in the outer plexiform layer of the retina. A freeze-fracture study in monkeys and rabbits. J Cell Biol 65:192-222.

Rieke F, Schwartz EA (1996) Asynchronous transmitter release: control of exocytosis and endocytosis at the salamander rod synapse. J Physiol 493:1-8.

Schwartz EA (1975) Rod-rod interaction in the retina of the turtle. J Physiol 246:617-638.

Sherry DM, Yazulla S (1993) Goldfish bipolar cells and axon terminal patterns: a Golgi study. J Comp Neurol 329:188-200.

Suzuki S, Kaneko A (1991) Protein kinase C-like immunoreactivity of the ON-type bipolar cell in goldfish and mammalian retinas: a useful criterion for subtype identification of isolated cells. Neurosci Res Suppl 15:S107-15.

Tachibana M, Okada T (1991) Release of endogenous excitatory amino acids from ON-type bipolar cells isolated from the goldfish retina. J Neurosci 11:2199-2208.

Tachibana M, Okada T, Arimura T, Kobayashi K, Piccolino M (1993) Dihydropyridine-sensitive calcium current mediates neurotransmitter release from bipolar cells of the goldfish retina. J Neurosci 13:2898-2909.

Tamalu F, Watanabe S (2007) Glutamatergic input is coded by spike frequency at the soma and proximal dendrite of AII amacrine cells in the mouse retina. Eur J Neurosci 25:3243-3252.

Teubner B, Degen J, Söhl G, Güldenagel M, Bukauskas FF, Trexler EB, Verselis VK, De Zeeuw CI, Lee CG, Kozak CA, Petrasch-Parwez E, Dermietzel R, Willecke K (2000) Functional expression of the murine connexin 36 gene coding for a neuron-specific gap junctional protein. J Membr Biol 176: $249-62$.

Umino O, Maehara M, Hidaka S, Kita S, Hashimoto Y (1994) The network properties of bipolar-bipolar cell coupling in the retina of teleost fishes. Vis Neurosci 11:533-548.

Veruki ML, Hartveit E (2002a) AII (rod) amacrine cells form a network of electrically coupled interneurons in the mammalian retina. Neuron 33:935-946.

Veruki ML, Hartveit E (2002b) Electrical synapses mediate signal transmission in the rod pathway of the mammalian retina. J Neurosci 22: $10558-10566$.

Vigh J, von Gersdorff H (2005) Prolonged reciprocal signaling via NMDA and GABA receptors at a retinal ribbon synapse. J Neurosci 25: 11412-11423.

von Gersdorff H, Matthews G (1994) Dynamics of synaptic vesicle fusion and membrane retrieval in synaptic terminals. Nature 367:735-739.

von Gersdorff H, Sakaba T, Berglund K, Tachibana M (1998) Submillisecond kinetics of glutamate release from a sensory synapse. Neuron 21:1177-1188.

Werblin FS, Dowling JE (1969) Organization of the retina of the mudpuppy, Necturus maculosus. II. Intracellular recording. J Neurophysiol 32:339-355.

Xin D, Bloomfield SA (1999) Comparison of the responses of AII amacrine cells in the dark- and light-adapted rabbit retina. Vis Neurosci 16: 653-665.

Zenisek D, Matthews G (1998) Calcium action potentials in retinal bipolar neurons. Vis Neurosci 15:69-75.

Zenisek D, Henry D, Studholme K, Yazulla S, Matthews G (2001) Voltagedependent sodium channels are expressed in nonspiking retinal bipolar neurons. J Neurosci 21:4543-4550.

Zhang J, Wu SM (2005) Physiological properties of rod photoreceptor electrical coupling in the tiger salamander retina. J Physiol 564:849-862. 